\title{
BREVE DIACRONÍA DEL AFORISMO SOCIALISTA "DE CADA CUAL SEGÚN SUS CAPACIDADES, A CADA CUAL SEGÚN SUS NECESIDADES”
}

\author{
Francisco Vigo Serralvo \\ Profesor interino de Derecho del trabajo y la Seguridad Social \\ Universidad de Málaga
}

Iuris praecepta sunt haec: honeste vivere, alterum non laedere, suum cuique tribuere (Ulpiano, Domicio, Digesto, 1, 1, 10, 1, año 533).

\begin{abstract}
El propósito de este estudio es describir sinópticamente el recorrido histórico del adagio socialista "de cada cual según sus capacidades, a cada cual según sus necesidades"; desde su origen hasta nuestros días. En esta descripción dedicaremos una especial atención a la paternidad intelectual de dicha máxima, cuestión controvertida que aspiramos, de algún modo, a esclarecer. Una vez ubicado su surgimiento histórico, expondremos la relevancia que adquirió en el debate mantenido por las distintas escuelas del socialismo utópico a la hora de determinar la justa distribución de las cargas y beneficios de la sociedad. Con posterioridad, analizaremos la referencia que hizo Marx a este principio de reparto cuando afirmó que su realización era el fin último al que aspiraba el proyecto comunista. Comprobaremos cómo, a raíz de este pronunciamiento marxista, los ensayos empíricos del comunismo - principalmente a través del referente de la U.R.S.S. - se dirigieron, al menos vocacionalmente, hacia la realización de este ideal de justicia distributiva. Cerraremos este estudio analizando la pervivencia actual de dicho ideal, cuestionándonos si presenta hoy algún grado de realización práctica y si mantiene vigencia en el debate político-filosófico contemporáneo.
\end{abstract}

The purpose of this study is to describe synoptically the historical path of the socialist adage "from each according to his abilities, to each according to his needs"; From its origins to the present day. In this description, we will pay special attention to the intellectual paternity of said distribution rule, a controversial issue that we aspire to somehow clarify. Once the historical origin of this aphorism is located, we will expose the relevance it acquired in the debate held by the different schools of French utopian socialism on justice in the distribution of the burdens and benefits of society. Later, we will refer to the reference that Marx made to this motto, affirming that its realization was the ultimate goal to which the communist project aspired. We will verify how, as a result of this Marxist pronouncement, the empirical tests of communism - mainly through the referent of the U.S.S.R. - were directed, at least vocationally, towards the realization of this ideal of distributive justice. We will close this study referring to the current survival 
of this distribution criterion, observing if it has some degree of practical realization today and if it is still valid in the contemporary political-philosophical debate.

Keywords: Utopian socialism, Marxism, communism, distributive justice, capabilities, needs.

Palabras clave: Socialismo utópico, marxismo, comunismo, justicia distributiva, capacidades, necesidades.

IUSLabor 3/2020, ISSN 1699-2938, pp. 239-283.

DOI. 10.31009/IUSLabor.2020.i03.10

Fecha envío: 10.08.2020 | Fecha aceptación: 9.11.2020

\section{Sumario}

1. Introducción.

2. Sobre la indeterminada filiación intelectual de la máxima.

3. La disputa protosocialista sobre la justa distribución de las cargas y los beneficios de la sociedad.

4. El reparto según las capacidades y las necesidades en el horizonte del proyecto comunista.

5. Sobre la vigencia actual de esta propuesta distributiva.

6. Bibliografía. 


\section{Introducción}

Aunque la máxima que preside el título de este trabajo será probablemente conocida por quien nos lee, valga precisar a efectos expositivos que se trata un principio de distribución de las cargas y beneficios del proceso de producción que ha llegado a constituir una divisa de ciertas ramificaciones del pensamiento socialista. Como se desprende de su literalidad, alude a un criterio de reparto en el que la asignación de los rendimientos económicos no es proporcional al desempeño profesional mostrado por el individuo. Tampoco enuncia una regla de repartición alícuota y per cápita de las obligaciones y derechos vinculados al proceso productivo. La literalidad a la que nos referimos sugiere un criterio de distribución en el que el trabajo se reparte en función del potencial laboral de cada sujeto, y los frutos que de dicho trabajo se deriven se adjudicarán en proporción a sus necesidades.

El propósito de este estudio es muy conciso: se limita a la descripción del recorrido histórico de este adagio, desde su formulación original; pasando por los primeros debates que surgieron en torno al mismo; por su inclusión entre los principios dogmáticos del comunismo; y llegando, finalmente, a la pervivencia marginal de dicho criterio de racionamiento en la discusión político-filosófica contemporánea.

De los distintos tramos en los que se dividirá este análisis, será el primero de ellos, el que se refiere a la formulación primigenia de este apotegma, el que acaparará una mayor atención expositiva. Y ello porque, como tendremos ocasión se comprobar, existen pronunciamientos contradictorios a la hora de determinar la paternidad intelectual de esta singular regla de reparto. Aunque hay ciertos aspectos metodológicos que dificultan averiguar de manera incontestable su autoría original, trataremos al menos de clarificar de algún modo esta cuestión, ordenando cronológicamente las primeras apariciones de este principio que hemos localizado en la literatura filosófico-política.

Precisamos, por lo demás, que este estudio se mueve por una vocación netamente descriptiva. No, por tanto, valorativa ni, en modo alguno, propositiva. Expresado de otra forma, los juicios sobre la legitimidad y factibilidad de este principio distributivo, sobre su carácter utópico o distópico, serán aquí adrede rehusados. Además, la pretensión de brevedad que se anuncia en el título descarta cualquier análisis exhaustivo u omnicomprensivo. Siendo inasumible referirse a todas y cada una de las ocasiones en las que se ha invocado esta regla de reparto, aquí relacionaremos solo algunas de las más relevantes de cada período.

Finalmente, como anotación metodológica, expresamos nuestra particular preferencia por la citación literal de los autores involucrados. En la medida que, como se verá, la temática 
que abordamos es sensible al tenor de las palabras empleadas, hemos preferido ofrecer al lector la posibilidad de conocer de manera directa - sin tergiversación ni omisión de los matices más sutiles - las distintas alocuciones que estimamos pertinentes para identificar el surgimiento de este principio y comprender el tratamiento que se le ha dado en las diferentes etapas de su historia.

\title{
2. Sobre la indeterminada filiación intelectual de la máxima
}

El principal interés académico que podrían adquirir estas páginas residiría, a nuestro modo de ver, en la disparidad de criterios habida entre los tratadistas del socialismo a la hora de ubicar temporalmente el origen de este aforismo y decantar su paternidad intelectual. Si hablamos de disparidad de criterios y no de disputa es porque, en lo que hemos podido comprobar, no se ha entablado entre estos autores ningún tipo de discusión historiográfica sobre el particular. Las alusiones al origen de este adagio suelen ser fugaces y tal cuestión no se ha tratado como un asunto sujeto a controversia que requiriese, por tanto, de un pronunciamiento aclaratorio y convincente. Cada uno de los autores que se han referido a ello han atribuido su formulación a un exponente del pensamiento socialista, sin cuestionarse la exactitud o rigurosidad de tal atribución.

Así, veremos con frecuencia - sobre todo en los estudios que se refieren al tema más superficialmente - atribuir este dictum a Karl Marx ${ }^{1}$; lo cual se justifica por su aparición ocasional en la Crítica al programa de Gotha ${ }^{2}$. En este opúsculo tardío del pensador de Tréveris se lee:

\begin{abstract}
"En una fase superior de la sociedad comunista, cuando haya desaparecido la subordinación esclavizadora de los individuos a la división del trabajo, y con ella, el contraste entre el trabajo intelectual y el trabajo manual; cuando el trabajo no sea solamente un medio de vida, sino la primera necesidad vital; cuando, con el desarrollo de los individuos en todos sus aspectos, crezcan también las fuerzas productivas y corran a chorro lleno los manantiales de la riqueza colectiva, sólo entonces podrá rebasarse totalmente el estrecho horizonte del derecho burgués y la sociedad podrá escribir en sus banderas: ¡De cada cual, según sus capacidades; a cada cual según sus necesidades!"'3.
\end{abstract}

\footnotetext{
${ }^{1}$ Por ejemplo, RAwLS, John, “A Theory of Justice”, en A.A.V.V., (edt. Kory P. Schaff), Philosophy and the Problems of Work: A Reader, Bostón, Rowman \& Littlefield Publishers, págs. 501-561; págs. 535. También, A.A.V.V. (Dir. Alain Renaut), Leçons de la philosophie, París, Odile Jacob, 2008, libro electrónico. TOURnIER, Maurice, Propos d'étymologie sociale. Tome 2: Des mots en politique, Lyon, Ena Éditions, 2002, pág. 93; GILABERT, Pablo, "The Socialist Principle "From Each According To Their Abilities, To Each According To Their Needs", Journal of social philosophy, vol. 46, núm. 2, 2015, págs. 197-225, pág. 197.

${ }^{2}$ MARX, Karl, Crítica del programa de Gotha, Elaleph, 2002 (origi. 1875). Libro electrónico.

${ }^{3}$ La cursiva es nuestra.
} 
Aunque Marx en aquella ocasión no identificó el origen de esta consigna ni aludió a ninguna fuente, tampoco, si atendemos al contexto discursivo en el que se ubica, parece pretender arrogarse adanísticamente su autoría. El tratamiento que da Marx a dicha frase es más bien el que se le daría a un lema previamente divulgado y popularizado. Asumiendo que materializar ese principio era uno de los objetivos tradicionales del comunismo, este autor solo estaría allí señalando el itinerario más eficaz para alcanzarlo. Aunque sobre esto volveremos más abajo, repárese ahora en que, a pesar del amplio "poder sintético" 4 de la frase, y a pesar de la magnitud transformadora del principio sustantivo que en ella se enuncia, s.e.u.o., será la única ocasión en la que la encontramos expresada literalmente en la vasta obra marxista ${ }^{5}$. Estimamos que si Marx hubiera pretendido presentarnos este particular principio distributivo como una idealización propia, le habría otorgado un mayor protagonismo narrativo.

Esta hipótesis, la que afirma que Marx aquí solo estaría invocando un principio previamente divulgado, se confirmará fácilmente si constatamos que, a la sazón, cuando Marx se refirió a él, este lema ya había sido empleado iterativamente por algunos de los —impropiamente llamados — socialistas utópicos. Sobre cuál de ellos lo hizo por vez primera encontraremos diversidad de pareceres. Así, para algunos analistas esta máxima habría sido formulada primigeniamente por Saint-Simon ${ }^{6}$. Otros autores, por su parte, consideran que su paternidad corresponde al conjurador de los iguales, François Babeuf ${ }^{7}$.

\footnotetext{
${ }^{4}$ Tomamos la expresión entrecomillada de De PABLO, Oscar, en un artículo intitulado "El a cada quien de acuerdo a sus necesidades de Marx: una interpretación antiutópica", publicado en Memoria: Revista de crítica militante. Accesible en https://revistamemoria.mx/?p=641 (último acceso el 31 de julio de 2020). En este artículo se lee la siguiente apología de este pronunciamiento marxista: "Esta consigna es célebre por su poder sintético, pero también por su naturaleza inusual dentro de la vasta obra de Marx. A diferencia de lo que ocurre por ejemplo en El capital (que no es más que una descripción crítica y minuciosa de la realidad presente), aquí se vislumbra algo parecido a una prescripción moral válida por sí misma, tan razonable que no requiere vincularse con ninguna realidad histórica particular. La frase es, en efecto, brillante como resumen de la moral subyacente a la política proletaria, pero por su ubicación en el texto, aparece exactamente como el tipo de afirmación que Marx rechazaba en sus adversarios como "receta utópica, aunque se trate de una receta genial".

${ }^{5}$ Solo hemos encontrado alguna mención incompleta a este principio de distribución. Aunque más abajo nos referiremos a ella, esta se encontraría en MARX, Karl y ENGELS, Frederich, La ideología alemana. Crítica de la novísima filosofía alemana en las personas de sus representantes FeuerbachI B. Bauer y Stirner y del socialismo alemán en las de sus diferentes profetas (trad. Roces, Wencesalo), Barcelona, Ediciones Grijalbo, 1974 (orig. Publicado en 1932, escrito entre 1845 y 1846), pág. 658.

${ }^{6}$ LuJÁn Palma, Eugenio: El derecho y la fuerza. Miguel de Unamuno: Desvelando la unidad de sentido y de su pensamiento, Sevilla, Punto Rojo, 2017, pág. 108.

${ }^{7}$ Dilas-RocherieuX, Yolène, "Totalitarisme et syndrome utopique: la spéficité de communisme" en A.A.V.V. (dir. Courtois, Stéphane), Quand tombe la nuit: origines et émergence des régimes totalitaires en Europe, Lausanne, L’Age d’Homme, 2001, págs. 281-291, pág. 284.
} 
Habrá quienes, sin embargo, le atribuirán este modesto mérito histórico a Louis Blanc ${ }^{8}$. Encontraremos también quien estime que se trataría de una frase insertada por Cabet $^{9}$ en su célebre Viaje a Icaria. Finalmente, algún autor ha afirmado que la invocación original de este adagio habría sido efectuada por August Becker ${ }^{10}$, un no muy renombrado socialista alemán de mediados del siglo XIX.

Valga precisar, de añadidura, que la confusión habida sobre la autoría de esta máxima viene propiciada, en buena medida, por la práctica frecuente en la época de citar información o pronunciamientos sin referir su procedencia - método el cual, estimamos, no es dable enjuiciar bajo los rígidos cánones contemporáneos de citación académica-. Si cada uno de los autores que expresó este enunciado hubiese indicado la fuente precisa de la que lo tomaba, resultaría mucho más fácil rastrear su formulación original y este primer apartado de nuestro estudio quizás carecería de objeto.

Dicho lo anterior, aclaramos que hemos encontrado una excepción a esta práctica, la cual nos puede servir como punto de partida para esclarecer la incógnita que ahora nos ocupa: Uno de los eventuales padres de este aforismo, Louis Blanc, al menos en una ocasión, nos remite a un precedente en el que él se apoya para presentarnos este principio distributivo. Concretamente nos señala al filosofo ilustrado Étienne-Gabriel Morelly y a su obra magna, Code de la Nature, de donde Blanc rescata la siguiente norma que debería regir en toda sociedad armoniosa: "Distribuir los trabajos según las fuerzas, los productos según las necesidades" ${ }^{11}$. Con todo, Blanc no identifica la página y la edición del Code de la Nature de la que provendría tal verbatim. En lo que nosotros hemos comprobado, esa concreta cita no se encontraría en el cuerpo principal de dicha obra, sino en el estudio preliminar que la introduce en la edición de 1841, titulado Analyse raisonnée du Système

\footnotetext{
${ }^{8}$ A Louis Blanc se la atribuyen, por ejemplo, Proudhon, Pierre-Joseph, Oeuvres complétes, Vol. 10, París, Librairie Internationale, 1868, pág. 84. Anglasell I SERRANo, Ramón, Compendio de las lecciones de economía política dadas en la Universidad de Barcelona, Barcelona, Imprenta Politécnica de Tomás Gochs, 1858, pág. 349; TREvor Cairns, El poder para el pueblo (trad. Tiara Ferrer, Montserrat) Torrejón de Ardoz, Akal, 1991, pág. 48; también Bunge, Mario y GABETTA, Carlos, ¿Tiene porvenir el socialismo?, Buenos Aires, EUDEBA, 2014; GIDE, Charles y PENIN, Marc, Coopération et économie sociale: 19041926, París, L Harmattan, 2005, pág. 282; MANIQUET, François, "De chacun selon ses capacités à chacun selon ses besoins, ou (même) plus, s'il le souhaite”, en Revue économique 2017/1 (Vol. 68), págs. 119 a 129; Savidan, Patrick, Dictionnaire des inégalités et de la justice social, París, Presses Universitaires de France, 2018; Johnston, David, A Brief History of Justice, Oxford, Wiley-Blackwell, 2011, pág. 182.

${ }^{9}$ LouIs Louvet, Curiosités de l'économie politique, París, Adolphe Delahays, 1861, pág. 17; AROCENA, Rodrigo, La crisis del socialismo de estado y más allá, Montevideo, Ediciones Tricle, 1991, pág. 37; A.A.V.V. (edits. GARY L. ANDERSON, KATHRYN G. HERR), Encyclopedia of Activism and Social Justice, Londres, SAGE Publications, 2007, pág. 366.

${ }^{10}$ FURNER James, Marx on Capitalism. The Interaction-Recognition-Antinomy Thesis, Leiden/Boston, Brill, 2019, pág. 113.

${ }^{11}$ BLANC, Louis, Histoire de la révolution française, Vol. 1, Labrairie du Figaro, París, 1846, pág. CLXI.
} 
social de Morelly y que fue redactado por el analista político François Villegardelle ${ }^{12}$. Este dato no es trivial, pues quizás no fuese impropio sumar a este último sujeto entre los potenciales artífices del aforismo que analizamos, en la medida que la alocución con la que sintetiza las normas distributivas morellianas guarda notable similitud en su literalidad con el lema socialista que ulteriormente popularizaría Karl Marx.

En cualquiera de los casos, aunque la frase transcrita por Blanc no fuese redactada por la pluma de Morelly, ello no nos impide afirmar que efectivamente este último abogó claramente por esta fórmula de racionamiento. Entre los múltiples pasajes del Code de la Nature en los que Morelly se refiere a esa idea, quizás los más taxativos los encontremos en la parte cuarta y última de la misma, en su "modelo de legislación conforme las intenciones naturales", donde este autor nos propone una serie de leyes fundamentales y sagradas con las que se erradicarían los vicios y todos los males de una sociedad. Entre otras y en lo que aquí respecta:

I. "Nada en la sociedad pertenecerá singularmente o en propiedad de nadie, excepto las cosas que hará uso actual, ya sea para sus necesidades, sus placeres o su trabajo diario.

II. Todo ciudadano será un hombre público, sostenido, mantenido y ocupado a expensas del público.

III. Todos los ciudadanos, por su parte, contribuirán a la utilidad pública, de acuerdo con sus fortalezas, talentos y edad; es sobre esto que sus deberes serán regulados, de acuerdo con las leyes distributivas" 13 .

Seguidamente, ya en sede de leyes distributivas o económicas, Morelly añade:

XI. "De acuerdo con las leyes sagradas, no se venderá ni se intercambiará entre conciudadanos, por lo que, por ejemplo, quien necesite algunas hierbas, verduras o frutas, irá y obtendrá lo que necesita [...] Si alguien necesita pan, irá y lo obtendrá por un tiempo marcado, de la persona que lo hace, y encontrará en la tienda pública la cantidad de harina para la del pan que debe preparar, ya sea por un día o más. Quien necesite una prenda la recibirá del que la compone; este último tomará las cosas del que lo hace, y el último sacará el material de la tienda donde lo habrán traído los que lo recogen: así que todas las demás cosas que se distribuirán a cada padre, para su uso y el de sus hijos"14.

\footnotetext{
${ }^{12}$ Villegardelle, François, Analyse raisonnée du Système social de Morelly, en Morelly, ÉtienneGabriel, Code de la Nature, París, Paul Masgana, Libaririe-Éditeur 1841, págs. 1-37, pág. 14. En esta opinión coincide Ernest Merson, al estimar que esa descripción de los principios morellistas es una glosa de Villegardelle que no coincide con la literalidad empleada por Morelly. Merson, Ernest, Du Communisme, réfutation de l'Utopie Icarienne, París, Garnier Frères, 1848, pág. 28.

${ }^{13}$ Morelly, Étienne-Gabriel, Code de la Nature...op.cit.,, pág. 152.

${ }^{14}$ Ibíd., págs. 154 y 155.
} 
Como decíamos, estos solo serían algunos de los pasajes en los que, quizás por su pretendido carácter normativo, la idea a la que aludimos aparece expresada de manera más manifiesta ${ }^{15}$. No obstante, en realidad la misma aparece transversal e iterativamente en el conjunto de esta obra de Morelly. De hecho, podría sostenerse que tal criterio distributivo fue una de las ideas más trascendentes, y a la sazón más transgresoras, de este ensayo $^{16}$. Dicho lo anterior, y sin salirnos del tema que nos ocupa, debería concluirse que Morelly no enunció este principio distributivo — no al menos en su Code de la Naturecon la formulación sintáctica con la que luego sería popularizado y en la que reside parte de su fuerza dialéctica. Podría decirse que fue el primero en proponer la idea distributiva que subyace tras este lema, pero eso tampoco sería del todo riguroso pues, en su esencia, esta particular forma de reparto encuentra antecedentes muchos más remotos que aparecen ya recogidos, a modo de ejemplo, en las Sagradas Escrituras de la cristiandad ${ }^{17}$ o, según algún autor ha mantenido, en la lógica de la obligation in solidum del Derecho romano ${ }^{18}$. Repárese, por si no hubiésemos aclarado ello con precisión, que en este primer apartado no buscamos el origen sustantivo o material de este canon distributivo -el cual quizás sea incunable - sino que, desde un criterio formalista o logomáquico, buscamos el origen de la formulación con la que alcanzaría posteriormente su mayor grado de difusión.

En cualquiera de los casos, dicho lo anterior y antes de concluir con Morelly, sí debe en justicia precisarse que, aunque este no acuñó dicha sentencia, ni tampoco formuló ex novo la idea sustantiva que la misma expresa, sí tuvo un papel protagonista al introducirla en el debate político de la época, dotándola además de una enjundiosa base teórica y argumentativa. Así lo aprecia Soboul, quien enumera entre las aportaciones de Morelly "un primer intento de configuración dogmática de los sistemas socialistas del siglo XIX: que cada uno contribuya según sus posibilidades y reciba según sus necesidades"19. Además, debe ponderarse la influencia que ejerció el Code de la Nature en el contenido de los ulteriores planteamientos socialistas.

\footnotetext{
${ }^{15}$ Otra referencia la encontramos en ibíd., pág. 69.

${ }^{16}$ Para constatar ello, podemos acudir, a título ejemplificativo a la acerada crítica efectuada por el escritor Jean-François de La Harpe, contenida en su Cours de littérature ancienne et moderne, Vol. 3, París, Chez Firmin-Didot Frères, Fils et $\mathrm{C}^{\mathrm{a}}$, Libraires, 1863 (original 1789), págs. 430 y ss. Como dato histórico, si acudimos a la crítica de esta obra vemos como esta se dirige contra Diderot, que es el autor al que se le imputó inicialmente la autoría Le Code de la Nature.

17 “La multitud de los creyentes tenía una sola alma y un sólo corazón. Nadie consideraba sus bienes como propios sino que todo lo tenían en común... No había entre ellos ningún necesitado, porque los que poseían campos o casa los vendían, y entregaban el dinero a los apóstoles, quienes repartían a cada uno según su necesidad". Evangelio de Lucas, libro de Hechos de los apóstoles. Capítulo 4, versículos 32-35.

${ }^{18}$ FURNER James: Marx on Capitalism...op.cit., pág. 113.

${ }^{19}$ Soboul, Albert, "Ilustración, crítica social y utopía durante el siglo XVIII francés", en A.A.V.V. (Droz, Jacques, dir.), Historia general del socialismo. De los orígenes a 1875, Barcelona, Destino, págs. 177-178.
} 
Esta influencia de Morelly en los socialistas decimonónicos se produce, principalmente, a través de Babeuf ${ }^{20}$, quien también se cuenta entre los potenciales artífices del aforismo que analizamos. En este autor ocurrirá algo similar a lo que acontecía en Morelly: sin descartar alguna omisión en nuestro escrutinio, no hemos encontrado en las principales obras de Babeuf ninguna referencia literal a dicha máxima, sin perjuicio de que en estas sí se mostrase partidario de la idea material de equidad que aquella incorpora. En efecto, aunque el conjurador de los iguales haya propugnado ocasionalmente un igualitarismo maximalista, estimando que "cada uno debe de soportar una cantidad igual de trabajo y obtener una parte igual de disfrute" ${ }^{\text {"21 }}$, en otros pasajes de su obra, passim, encontraremos matizaciones o excepciones a ese axioma que apuntan hacia un ideal de igualdad material cuya consecución exige participaciones desiguales en las cargas y beneficios de la comunidad. En estos otros pasajes sí señalará que la contribución social de cada individuo debería guardar relación con sus capacidades y los criterios de reparto deberían estar orientados a la estricta satisfacción de las necesidades de la colectividad, sin margen para el acaparamiento excesivo de bienes. Así se le lee:

\begin{abstract}
"Pero, ¿qué entendemos por comunidad de trabajo? ¿Queremos que todos los ciudadanos estén sujetos a las mismas ocupaciones? No; pero queremos que se distribuya el trabajo diferente para no dejar ocioso a un solo individuo válido; queremos que el aumento en el número de trabajadores garantice la abundancia pública, disminuyendo así la pena individual; queremos que, a cambio, todos reciban de la patria lo suficiente como para satisfacer las necesidades naturales y la pequeña cantidad de necesidades ficticias que todos pueden satisfacer"22.
\end{abstract}

En cualquiera de los casos, como decimos, Babeuf no sintetiza esta proposición distributiva bajo la formulación literal con la que después se haría más célebre. Sí cabría estimar, empero, que abogó por ese criterio de reparto y que quizás propició que este llegase desde Morelly hasta los socialistas del siglo XIX.

Con mayor brevedad descartaremos que fuese Saint-Simon quien acuñara la locución que aquí analizamos. No hemos encontrado en sus principales obras ninguna alusión explícita a la misma y, además, se mostró partidario de un criterio de reparto muy dispar al allí

\footnotetext{
${ }^{20}$ En palabras ahora de Fetscher, "es evidente que el Code de Nature influyó, por intermedio de Babeuf, en el primitivo socialismo del Siglo XIX, constituyendo del puente entre Moro y el socialismo proletario" FeTSCher, Iring, Socialismo. De la Lucha de Clases al Estado Providencia, Barcelona, Plaza \& Janes, 1977 (orig. 1968, J. Ruíz), pág. 57.

${ }^{21}$ BABEUF, Grachus, Conspiration pour l'églité, Bruselas, Librairie Romatique, 1828, págs. 142 y 143.

${ }^{22}$ Ibíd., pág., 143. Más adelante en esta misma obra indicará que la participación laboral del sujeto será "proporcionales a su fuerza y a la dureza del trabajo", pág. 211, y "según las necesidades de la nación y según el principio supremo de igualdad”, pág. 210.
} 
enunciado. Si algunos han sostenido que este autor fue el primer formulador de esta máxima, ello podría deberse a que se le ha atribuido una sentencia que guarda cierta similitud sintáctica con la que nosotros analizamos. Concretamente, al catequista industrial se le habría imputado la siguiente frase: "cada uno según su capacidad, a cada capacidad según sus obras". Aunque sobre esto volveremos más abajo, dos apreciaciones caben ahora: 1) Existen voces historiográficas que descartan que esta otra forma de reparto fuese enunciada verdaderamente por Saint-Simon, siendo más bien el resultado de la reinterpretación de su mensaje efectuada por algunos de sus epígonos. 2) En cualquiera de los casos, el criterio distributivo que contiene esta sentencia difiere ampliamente del que nosotros venimos analizando. Sobre ello, insistimos, volveremos en el siguiente epígrafe.

Pasamos ya al cuarto - en estricto orden cronológico — de los potenciales artífices del dictum que estudiamos: Louis Blanc. Este es, quizás, el autor al que más reiteradamente se le ha atribuido la formulación de dicho aforismo, inclusive por los analistas de su época, a los cuales atribuimos un mayor crédito en la medida que no se habrán visto influenciados por fuentes secundarias. Además, a diferencia de otros autores, Louis Blanc se arrogará a sí mismo la ideación de ese principio de reparto ${ }^{23}$. Finalmente, de entre todos los pensadores que se disputan su paternidad intelectual, será Blanc el que más frecuentemente la invoque y el que la dote de un mayor soporte argumentativo. Por todas estas razones le dedicaremos a este personaje una especial atención.

Las referencias que Blanc hará a esta regla distributiva se encuentran concentradas principalmente en su obra más célebre, L'Organisation du Travail. En esta obra Blanc defiende la conveniencia de este criterio de reparto en la medida que es el único que asume la diferencia natural de cada uno de los individuos, promoviendo un reparto formalmente desigualitario de las cargas y beneficios de la sociedad tendente a compensar aquellos desequilibrios originales. La fundamentación última de este principio distributivo es por tanto de origen naturalista y descansa sobre la irregular distribución divina de los dones. Así desarrolla Blanc esta argumentación:

"Hay dos cosas en el hombre: necesidades y facultades. Por necesidad, el hombre es pasivo; por facultades, él es activo. Por necesidad, llama a sus semejantes en su ayuda: por las facultades, se pone al servicio de sus semejantes. Las necesidades son la indicación que Dios le da a la sociedad. Entonces se debe más al que tiene más necesidades, y está permitido exigir más al que tiene más facultades. Por lo tanto, de acuerdo con la ley divina escrita en la organización de cada hombre, una mayor

\footnotetext{
${ }^{23}$ BLANC, Louis, Histoire de la révolution de 1848, vol. 2, París, A. Lacroix, Verbeoeckhoven et Ca 1870 , pág. 37. En este mismo sentido, Blanc, Louis, Révélations historiques en réponse au livre de lord Normamby, Brúselas, Mleline, Cans et Compagnie Editeurs, 1859, pág. 42.
} 
inteligencia supone una acción más útil, pero no una retribución más considerable; y la desigualdad de aptitudes solo puede conducir legítimamente a la desigualdad de deberes. La jerarquía por capacidades es necesaria y fructífera; la retribución por capacidades es más que fatal, es impía".

Para lo que ahora nos interesa debe indicarse que las primeras ediciones de L'Organisation $d u$ Travail datan del año 1839. Sin embargo - esto es sumamente relevante- en estas primeras tiradas de la obra no encontraremos ninguna alusión a esta singular regla distributiva. Es más, incluso en alguna de estas tempranas ediciones observaremos la proposición de criterios de reparto diferentes, basados en una asignación igualitaria percápita de los resultados de la producción ${ }^{24}$. Será solo más adelante, a partir de la novena edición de dicha obra, datada en el año 1850, cuando aclarará que ese otro reparto igualitario solo resultaría legítimo de forma transitoria, pero que con él no se alcanzaba una verdadera distribución justa. Así se expresaba en estas últimas versiones:

\begin{abstract}
"Mostrar la meta y entrar en el camino que conduce a ella es todo lo que es posible hoy en día, dada la dirección incorrecta de los hábitos y la falsedad de las nociones generales. Es por eso que he hablado de la participación equitativa en las ganancias, $e$ incluso de la igualdad salarial, ya sea en ediciones anteriores de este libro o en Luxemburgo. Pero, que no se olvide: esto nunca ha sido propuesto por mí, excepto como una medida de transición”25.
\end{abstract}

Esta última literalidad se inserta en una extensa palinodia en la que Blanc constata las lecturas erróneas que se habían efectuado de las ediciones precedentes de L'Organisation du Travail; tratando ahora de ser más explícito en la exposición de su ideal distributivo. Como puede leerse, con la implementación coyuntural de un criterio formalmente igualitario solo pretendería la deshabituación de las costumbres y vicios adquiridos en el defectuoso orden capitalista. Será ya en estas ediciones más tardías donde aclarará que su verdadero ideal de justicia distributiva pasaría por un reparto formalmente desigual, atendiendo a las concretas capacidades y necesidades de cada sujeto, lo cual solo sería realizable una vez que se hubiesen superado las trabas fácticas que imponía el régimen capitalista. Entre estas trabas, se refiere Blanc al carácter excluyente de la educación, que impedía que las facultades de cada uno pudieran ser objeto de una medida exacta; o al

\footnotetext{
${ }^{24}$ En su propuesta de reglamentación para los talleres sociales (art. 27) propondría que los asociados "fuesen pagados por piezas o por jornadas, y cada uno recibe según su fuerza y su capacidad. Esto no será, para los beneficios generales del año, de los que todos toman una parte igual. Sin embargo, si un número de socios, basándose en principios distintos a los establecidos anteriormente, no quisieran ganar más que los demás, se les daría la masa de su salario, y lo compartirían como ellos lo oirían; o la gerencia y los líderes del grupo harían esto por capricho a voluntad de aquellos que lo desearan, para que cada uno tuviera la misma participación". Blanc, Louis: Organisation du travail, $5^{\text {a }}$ ed. París, Au Bureau de la Société Fraternelle, 1846, pág. 283.

${ }^{25}$ Blanc, Louis, Organistaion du Travail, $9^{\mathrm{a}}$ ed, París, Au Bureau du Nouveau Monde, 1850, pág. 75.
} 
sistema social, que habría oscurecido las leyes de la naturaleza e "impuesto una gran cantidad de necesidades ficticias, gustos depravados, y deseos vanos". En tal estado de cosas, la aplicación prematura de un reparto según las necesidades correría el riesgo de "ver a muchos trabajadores hacer muy poco y exigir demasiado"26. Así y según Blanc, la equidad distributiva solo sería un sustitutivo coyuntural, válido en tanto que se alcanzase una cooperación general entre los trabajadores y se eliminasen los rasgos de ajenidad en las relaciones laborales ${ }^{27}$. Pero esta medida transitoria, aclara, no debería alejarnos del verdadero criterio distributivo que, según insiste Blanc, habría defendido inmutablemente a lo largo de toda su trayectoria, aunque de manera algo implícita ${ }^{28}$. Según puede leérsele:

"La verdad es que, siempre e invariablemente, he colocado la solución real al problema de la distribución equitativa en la combinación de fuerzas para la producción, de productos para el consumo, teniendo en cuenta las facultades de cada uno. de sus necesidades." ${ }^{29}$ [...] "iDios prohíbe, además, que consideremos la igualdad salarial como la realización completa del principio de justicia! La fórmula real es esta: deje que todos produzcan de acuerdo con su aptitud y sus fortalezas, que cada uno consume de acuerdo con sus necesidades" 30 .

Conviene reparar en la aplicación gradual o bifásica de esta regla de reparto que nos propone Blanc, pues comprobaremos después la coincidencia que en este sentido se produce con el planteamiento marxista. En lo que a nosotros por ahora nos atañe, debe precisarse que, aunque sea en L'Organistation du Travail donde aparecerá de manera más desarrollada la fundamentación de este criterio de reparto, cuando Blanc se refiere al mismo lo hace remitiéndose a un discurso previo, pronunciado en la Comisión del Luxemburgo ${ }^{31}$ y publicado en el Moniteur del 3 de abril de $1848^{32}$. En otras ocasiones en

\footnotetext{
${ }^{26}$ Ibíd., pág. 74 y 75.

27 "En un taller donde cada trabajador trata de forma aislada, por separado con el empresario, con lo que hasta la Revolución habíamos llamado el maestro, ¿a quién le interesa que su vecino cumpla concienzudamente su tarea? ¿A quien le importa? Trabajamos en nombre de otros, en beneficio de otros: si mi compañero se cruza de brazos, ¿qué me pongo?”, ibíd., Pág. 75.

${ }^{28}$ Ibíd., pág. 76.

${ }^{29}$ Blanc, Louis, Organistaion du Travail, $9^{a} \ldots$ op.cit., pág. 74.

${ }^{30}$ Ibíd., pág. 76.

${ }^{31}$ Nos referimos a la comisión para la cuestión obrera, creada como pseudoministerio de trabajo durante el desarrollo de la Revolución de Febrero de 1848, atendiendo así a una de las principales reivindicaciones obreras. Fue liderada por Blanc y tuvo su sede en el palacio parisino del Luxemburgo. Sobre las creación y significado de esta comisión, vid. Vigo Serralvo, Francisco, El derecho al trabajo, un primigenio y alternativo proyecto de Estado social. Reflexiones para el debate sobre la cuestión social contemporánea, Cizur-Menor, Aranzadi, 2019, págs. 227 y ss.

${ }^{32}$ La versión publicada de ese pronunciamiento que hemos localizado se encuentra en BLANC, Louis, La Révolution de Février au Luxembourg, París, Michel Lévy Frères, 1848, pág. 75. Compartiendo nuestra
} 
las que Blanc ha mencionado este principio, también ha remitido a dicho discurso ${ }^{33}$. Este dato resulta trascendente en nuestra inquisición, pues descarta que la primera enunciación de esta regla por parte de Blanc estuviese presente en las ediciones previas de L'Organisation du Travail. Por tanto, debe rechazarse que la formulación de Blanc de este lema date del año 1839 - primera edición de dicha obra - como algunos autores han sostenido $^{34}$. De esta forma, como de seguida vamos a comprobar, podríamos descartar que fuese Blanc el verdadero artífice de la máxima que analizamos.

Y es que si aceptamos, como el propio Blanc admite, que la primera alusión explícita que este hizo a tal regla de reparto data del año 1848, puede comprobarse que existen en la literatura social referencias previas a la misma. Para constatar ello pasemos ahora a otro de los autores que se han incluido entre los potenciales artífices de este apotegma socialista, Etienne Cabet. Este último autor se mostrará partidario de la idea sustantiva de reparto según capacidades y necesidades desde las primeras ediciones de su célebre Viaje a Icaria, datadas en el año 1844. Es más, ya la encontramos expresada en el precedente de dicha obra, Voyage et aventures de Lord Villiam Carisdall en Icarie, que fue escrito en Londres en 1840 bajo el seudónimo de Francis Adams ${ }^{35}$. Concretamente será en la tercera parte de esta obra, intitulada Resumen de la doctrina o de los principios del comunismo, donde encontremos una defensa expresa de este criterio de asignación de bienes y obligaciones.

“¿Cuál es el principio en relación á los derechos y á los deberes? -Ellos son los mismos para todos; cada uno tiene el deber de trabajar el mismo número de horas cada día , según sus fuerzas y capacidad; y cada uno goza del derecho de recibir una parte igual de los productos según sus necesidades" ${ }^{36}$.

tesis, según la cual esta sería primera utilización de este aforismo por parte de Blanc, c.fr. BovENs, Luc y LuTZ, Adrien, "From Each according to Ability; to Each according to Needs: Origin, Meaning, and Development of Socialist Slogans", History of Political Economy, vol. 51:2 (2019), págs. 237-257, págs. 238 y 239.

${ }^{33}$ BLANC, Louis, "Eclaircissement sur les doctrines du Luxembourg", en Le Nouveau monde: journal historique et politique, París, Bureau D’Abonnement, 1849, Volumen 2, págs. 126 a 142, pág. 142.

${ }^{34}$ MANiQUET, François, "De chacun selon ses capacités à chacun selon ses besoins, ou (même) plus, s'il le souhaite", en Revue économique 2017/1 (Vol. 68), págs. 119 a 129; Savidan, Patrck, Dictionnaire des inégalités et de la justice social, París, Presses Universitaires de France, 2018.

${ }^{35}$ Las primeras ediciones de 1840 publicadas bajo el seudónimo de Admas, Francis y el título de Voyage et aventures de Lord Villiam Carisdall en Icarie, T. II, Paris, Hyppolyte Souverain, 1840, pág. 496

${ }^{36}$ CABET, Etienne, Viaje por Icaria, (trad. Francisco Javier Orellana), Barcelona, Imprenta y Librería Oriental, 1848, pág. 94. En el original, Cabet, Etienne, Voyage en Icarie, París, Au burueau du populaire, 1846, pág. 557. Estas líneas se encuentran igualmente expresadas en las primeras ediciones de 1840, Voyage et aventures de Lord Villiam...op.cit., pág. 496. 
Este extracto nos resulta relevante por dos motivos. En primer término, por incorporar una redacción bastante similar a la que luego adquiriría este principio distributivo en su formulación más popular. En segundo lugar, y quizás con más relevancia, por incluirlo entre los principios rectores de un modelo ideal de convivencia aún en ciernes y con escaso bagaje teórico: el comunismo. Por otro lado, en ediciones posteriores de la singladura icariana, las que van desde 1845 en adelante, esta regla de reparto adquiere una mayor importancia, ubicándose en la misma portada de la obra con una redacción que es casi coincidente con la que llega a nuestros días: "Primer derecho: vivir cada uno según sus necesidades"; "primer deber, trabajar cada uno según sus fortalezas",37. No es de extrañar, por tanto, que algunos autores, también de aquella época, asuman sin discusión que es Cabet el creador de este singular lema sobre la partición de los bienes sociales.

Dicho lo anterior, sin embargo, sigue siendo esta última atribución en alguna medida discutible. Recordemos que todavía nos resta por aludir al último de los que se han señalado como eventual formulador de este lema socialista. Nos referimos a August Becker $^{38}$, un no muy renombrado periodista y político alemán que ha sido preterido de los principales anales contemporáneos del socialismo. A este último autor nos remite James Funer ${ }^{39}$, quien señala que la primera alusión histórica a este principio distributivo la encontraríamos en pequeño un opúsculo de Becker intitulado Was wollen die Kommunisten $?^{40}$ — ¿Qué quieren los comunistas?, en lo que sabemos no traducida del alemán a cualquier otra lengua - y que en realidad es la reproducción de un discurso pronunciado por Becker el 4 de agosto de 1844 en Lausana, en el seno de una asamblea organizada por miembros de diversas asociaciones de trabajadores. Si acudimos a este pronunciamiento encontraremos, en efecto, una referencia literal al criterio de reparto al que estamos aludiendo. Además, veremos cómo Becker nos presenta esta regla como el principio esencial del comunismo y nos ofrece un razonamiento sobre los fundamentos en los que descansaría su mayor legitimidad. Ciertamente ya Cabet con alguna antelación incluyó el meritado criterio de reparto entre los principios esenciales del comunismo; el matiz que con cierta relevancia introduce Becker es el de elevarlo al principio básico no uno más de los principios - de esta corriente política. Veamos la referencia que hace

\footnotetext{
${ }^{37}$ Edición de 1848, París, Au Bureau du Populaire. Otros autores han constatado que este eslogan se insertará en la portada de esta obra desde la edición del año 1845. Vid., Bovens, Luc y LuTZ, Adrien, "From Each according to Ability...op.cit., pág. 239.

${ }^{38}$ Para una breve semblanza de Becker, vid. A.A.V.V. (ed. William D.P. Bliss), “August Becker”, en The New Encyclopedia of Social Reform, Including All Social-Reform Movements and Activities, and the Economic, Industrial, and Sociological Facts and Statistics of All Countries and All Social Subjects, Nueva York, Funk and Wagnalls Co, 1908; pág. 102.

${ }^{39}$ FURNER James, Marx on Capitalism... op.cit., pág. 113.

${ }^{40}$ Lausana, Kommunistischer-Verein, 1844.
} 
Becker a este criterio de reparto, la cual se inserta en una alocución sobre las iniquidades distributivas del capitalismo y la necesidad de reducir los tiempos de trabajo:

"El principio básico en el comunismo es: de cada uno según sus habilidades, a cada uno según sus necesidades. Me gustaría señalarlo, no se lee: todo el mundo de acuerdo con una habilidad que, en opinión del grupo grande y la ayuda de un determinado cuerpo social, debería ser realizada. Muchos piensan que las diferentes habilidades también deberían ser recompensadas cuantitativamente de manera diferente. Según ellos, las habilidades y logros de la persona deberían ser la medida de los salarios que la sociedad le debía. Los comunistas pensamos lo contrario. En nuestra opinión, las habilidades del individuo indican lo que debe el individuo a la sociedad, y no lo que la sociedad le debe al individuo en el reparto material. Todas las habilidades del individuo pertenecen a la sociedad y son igualmente necesarias e igualmente valiosas para ellos. El minero, que cava metal, es necesario para que prospere, al igual que el poeta, que idolatra y eleva a través de las formaciones de una fantasía. ¿Por qué debería uno ser recompensado materialmente mejor que el otro? [...] Lo que distingue al poeta del mecánico son sus distintas habilidades, es un criterio que se basa en el azar. ¿Ambos son iguales como humanos, aunque de manera diferente como individuos? ¿No tenían los dos la necesidad, el deseo, el deseo de ser felices dentro de sus corazones? Qué bárbaro dejar que el minero pague que no es poeta. Hay socialistas que quieren recompensar el trabajo duro de manera más lucrativa que los trabajos más fáciles. Pero eso es injusto. Cada uno debe hacer lo que pueda, el trabajo duro para el fuerte, para el débil el fácil y cosas por el estilo; y luego deben decidir los deseos, las necesidades y la buena voluntad; si el minero debe tener una comida más fuerte y nutritiva que el poeta, qué comida puede tener, y viceversa" ${ }^{\prime 4}$.

De este modo, cerrando este primer apartado de nuestro estudio con una breve síntesis o recapitulación, y para tratar de dar respuesta al interrogante de partida o, de algún modo, clarificarlo: concluiremos que fue Morelly quien se encargó de introducir en el discurso filosófico de la época la idea sustantiva de distribución a la que aludimos. Cuestión más intrincada es la de determinar quién habría sido el artífice del giro de cada uno según sus capacidades, a cada uno según sus necesidades. En lo que hemos comprobado, s.e.u.o., Morelly no enunció tal frase ni otras similares. François Villegardelle, glosando el mensaje morelliano, sí introduce en 1841 una sentencia bastante afín a aquella, con apenas algunas variaciones menores. Igualmente hizo Cabet a comienzos del año 1840, presentando además este criterio distributivo como una de los principios fundamentales del comunismo, pero sin llegar a alcanzar del todo la concreta literalidad con la que se popularizaría años más tarde. Así, si somos escrupulosos en los aspectos formales o logomáquicos, concluiríamos que fue August Becker el que, en agosto de 1844, habría pronunciado explícitamente y por vez primera el adagio que venimos analizando. Si bien

${ }^{41}$ Ibíd., págs. 34 y 35. 
este es a nuestro juicio un dato relativamente anecdótico, en la medida que ese principio de distribución había sido ya expuesto en la literatura social precedente bajo formulas sintácticas muy similares. Becker solo la expresó de un modo en el que a la postre, y quizás casualmente, adquiriría mayor popularidad.

Con todo, advertimos que la conclusión que aquí presentamos es susceptible de refutación en la medida que determinar apodícticamente la primera formulación de este principio exigiría un cotejo omnicomprensivo y exhaustivo de toda la literatura social de la época. Admitimos que ese tan ambicioso escrutinio no ha sido en este caso ejecutado. Además, no debe descartarse la existencia de manuscritos, borradores o alocuciones que no fueron publicadas o que no hayan llegado a nuestros días y que revelen otra paternidad intelectual para este célebre adagio socialista.

\section{La disputa protosocialista sobre la justa distribución de las cargas y los beneficios de la sociedad}

Aclarada así la controvertida paternidad intelectual de este lema, en este nuevo epígrafe nos proponemos contextualizar la aparición de este en los primeros debates doctrinales del protosocialismo. Y es que, como ya dijimos, con carácter previo a que fuese invocada por Marx aquella sentencia había adquirido ya un relativo grado de reconocimiento. Ello se debe, en parte y según nuestra opinión, a la confrontación que se dio entre las proposiciones distributivas que postularon las diferentes escuelas o corrientes del pensamiento socialista francés. Aunque será el principio distributivo que nosotros estudiamos el que ulteriormente adquiriría un mayor grado de difusión, en su momento genético coexistió con otras alternativas que pugnaban por consolidarse como el principio rector del orden social y económico. De hecho, estimamos que la concreta literalidad adquirida por el aforismo que analizamos se explica mejor a través de este debate. En lo que sigue vamos a tratar de dar soporte a esta apreciación.

Un testimonio de esta disputa intelectual nos lo da, entre otros, el economista político de la época Joseph Garnier:

"Saint-Simon os dice: a cada uno según su capacidad, y a cada capacidad según sus obras. Fourier os dice: a cada uno según su capital, su trabajo y su talento. Morelly os dice: A cada uno según sus necesidades. Yo me atrevo a deciros: A CADA UNO SEGÚN SU TRABAJO [sic]. Fourier y Saint-Simon reconocen los derechos individuales sobre la sociedad, además de una participación positiva en el trabajo común. Morelly y los 
comunistas de su escuela imponen los deberes individuales hacia la sociedad, como resultado de una participación cualquiera en el producto común" ${ }^{42}$.

Tal porfía, omitiendo otros referentes de ociosa $\operatorname{cita}^{43}$, se encuentra también recogida en algún análisis retrospectivo, en el que puede leerse:

"Si los saint-simonianos han fundado el principio de la sociedad sobre la siguiente fórmula: a cada uno según su capacidad, a cada uno según sus obras, los foureristas han basado su sociedad ideal sobre otra regla de reparto: a cada uno según capital, según su trabajo, según su talento, mientras que Blanc, siguiendo a Morelly, resumen la clave de la sociedad con las siguientes palabras: De cada uno según sus facultades, a cada uno según sus necesidades" ${ }^{4}$.

Los dos pasajes que hemos transcrito - el primero de ellos datado en el año 1844 y el segundo en el año 1929 - nos revelan varios aspectos trascendentes para nuestro estudio, a saber: 1) La ya aludida concurrencia de proposiciones distributivas heterogéneas en el seno del pensamiento protosocialista francés. 2) La asociación que se hizo desde un comienzo entre el comunismo y el criterio de reparto según las capacidades y necesidades. 3) Finalmente, la imputación a Morelly de la autoría de este planteamiento. Esto último, en el segundo de los pasajes se matiza para atribuirle su formulación a Blanc, si bien admitiendo la influencia que sobre este ejerció Morelly. De pasada y enlazando con lo abordado en el epígrafe anterior, esta errónea atribución, la referente a Blanc, demuestra una vez más la confusión habida en torno a la autoría de este lema socialista. Nosotros hemos concluido que Blanc no incorporó ninguna originalidad al referirse al mismo, ni en el plano sustantivo, ni en el formal o semántico. No obstante lo anterior, y en relación con el debate que abordamos ahora en este epígrafe, las referencias a Blanc como exponente de esta postura teórica pueden encontrar justificación. $\mathrm{Y}$ es que, según veremos, este participó intensamente en el debate dialéctico sobre el prorrateo de las cargas y beneficios de la sociedad, contribuyendo así decisivamente en la difusión de dicho lema.

Para desarrollar los términos en los que se desenvolvió esta discusión doctrinaria tomaremos como punto de partida el criterio de distribución proclamado por la escuela saint-simoniana: de cada uno según su capacidad, a cada capacidad según sus obras.

\footnotetext{
${ }^{42}$ GARNIER, Joseph, Traité D Économie Politique Sociale ou industrielle, París, Garnier Frères, Guillaumin et Ca, 1868, pág. 488.

${ }^{43}$ V.gr., Proudhon, Joseph, Euvres complètes de P.-J. Proudhon: Quèst-ce que la propiété?, Librairie Internationale, París, 1873, págs. 97 a 99; VIDAL, François, De la répartition des richesses, ou, De la justice distributive en économie, París, Capelle Libraire-Editeur, 1846, pág. 396 y ss.

${ }^{44}$ Pechan, Hermann, Louis Blanc als Wegbereiter des modernen Sozialismus, Viena, Jena, G. Fischer, 1929, pág. 76.
} 
Más arriba, nos referíamos a este otro lema y comprometíamos un tratamiento más desarrollado, el cual abordamos ahora para indicar que, aunque esta idea de reparto fue ciertamente imputada a Saint-Simon, en lo que hemos podido comprobar ninguna alusión a la misma aparece en las principales obras del catequista industrial. Por contra, sí que la encontramos expresada por alguno de los comentaristas que póstumamente difundieron su mensaje. A modo de ejemplo, se encuentra expresada en la anónima Doctrine de SaintSimon publicada en el año 1828. Así se leía allí:

“¿Qué es eso de la a transmisión de la fortuna de padres a hijos sin más razón que la filiación de sangre, si no el más inmoral de todos los privilegios, eso de vivir en sociedad sin trabajar o de ser recompensado más allá de sus obras?

Triste ciencia, que habría mantenido la servidumbre, quien habría defendido a Jesús de predicar la fraternidad humana, en el miedo que su palabra no ha llegado a los oídos de un esclavo, itriste ciencia, la cual, en una época más remota de nuevo, haría celebre la justicia de la antropología!

Sí, todos nuestros teóricos políticos tienen los ojos puestos hacía el pasado, esos mismos, esos sobre todo que pretenden la dignidad del futuro; aquellos a los que nosotros les anunciamos que el reino del TRABAJO [sic] llega, que el de la OCIOSIDAD [sic] ha acabado, ellos nos tratan de soñadores; ellos nos dicen que los hijos siempre heredan de su padre, como un pagano habría dicho que el hombre libre tendrá siempre esclavos; pero la humanidad ha sido proclamada por Jesús: ¡NO MÁS ESCLAVITUD! por Saint-Simon se ha escrito: Cada uno según su capacidad, a cada capacidad según sus obras, ¡NO MÁS HERENCIA! ${ }^{45}$.

Del párrafo reproducido puede deducirse fácilmente que con este otro lema se propugnaba un criterio de reparto meritocrático, basado únicamente en la contribución productiva que cada cual haya efectuado a la sociedad. De esta forma, se contrapone a la transmisión hereditaria de la riqueza y a la asignación de rentas por la pertenencia a una determinada clase social. Si bien estas ideas son en parte coherentes con el genuino ideario de SaintSimon, es dudoso que fuesen expuestas directamente por él. En efecto, a juicio de algunos autores de aquel momento, este razonamiento, tal y como ha sido transcrito, no sería más que una apócrifa variación del mensaje saintsimoniano original ${ }^{46}$. Más concretamente, esta reformulación se le ha atribuido a los Pères Suprêmes del saintsimonismo,

\footnotetext{
${ }^{45}$ Anónimo, Doctrine de Saint-Simon, Exposition, Bruselas, Louis Hauman et Compagnie, 1829, pág. 28.

${ }^{46}$ LOMENIE, Louis-Léonard, Galerie des Contemporains illustres, par un homme de rien, T.II., Bruselas, Meline, Cans, et compagnie, 1848, pág. 616. Compartiendo este mismo parecer, el biógrafo de Blanc, Edouard Renard, afirmaba: "Los líderes de la religión de Saint-Simon declararon que rechazaban la comunidad de bienes y la distribución equitativa de la propiedad, ya que eran herejías que violaban la primera de las leyes morales e incompatibles con el orden social y la asociación, incluida la desigualdad. es la base y la condición esencial; pero exigieron que se aboliera la herencia, que todos los instrumentos de trabajo, tierra y capital, formando el fondo fragmentado de todas las propiedades particulares, fueran explotados, asociados y distribuidos jerárquicamente, de modo que cada uno tuviera medios de producción proporcionales a su habilidad y disfrute según sus obras" EDOUARD, Renard, Louis Blanc. Sa vie, son oeuvre, Librairie Hachette, 1923, pág. XVIII.
} 
Barthélemy Prosper Enfantin y Saint-Amand Bazard ${ }^{47}$. Y es que, si acudimos a los textos originales de Saint-Simon comprobaremos, no solo que estos omiten cualquier referencia a aquel principio distributivo, sino que incluso en alguna ocasión recusaron expresamente la legitimidad o conveniencia de adoptar cualquier patrón centralizado para la repartición de los bienes sociales. Valga el siguiente pronunciamiento como botón de muestra:

\begin{abstract}
"En mi opinión, el único objetivo al que deben tender todos los pensamientos y todos los esfuerzos es la organización más favorable a la industria, a la industria entendida en el sentido más general y que abarca todo tipo de trabajo. útil, la teoría como la aplicación, los trabajos de la mente como los de la mano; la organización más favorable para la industria, es decir, un gobierno donde el poder político tiene acción y fuerza solo lo que es necesario para evitar que se perturbe ese trabajo útil, un gobierno donde todo está ordenado para que los trabajadores, cuyo sindicato forma la sociedad real, puedan intercambiar directamente entre ellos y con total libertad los productos de sus diversas obras, un gobierno como la sociedad, que solo puede saber lo que le conviene, lo que quiere. lo que ella prefiere es también el único juez del mérito y la utilidad del trabajo y, en consecuencia, que el productor solo tiene que esperar del consumidor solo el salario de su trabajo, la recompensa por su servicio, lo que sea cualquier nombre que le guste elegir" 48 .
\end{abstract}

Como decíamos, en este último extracto podemos apreciar cómo Saint-Simon, antes que por una distribución planificada de los recursos, se mostró partidario del libre intercambio como fórmula para la asignación de las ganancias obtenidas en el proceso industrial. Como con algún sarcasmo expresó el ensayista Louis-Léonard de Loménie: “compare estas ideas muy juiciosas sobre el futuro con la dictadura de los dos o tres pontificios encargados de distribuir a cada uno según su capacidad y a cada capacidad según sus obras, y estará de acuerdo en que Saint-Simon fue perfeccionado singularmente por sus discípulos"49. A colación de este último comentario, de añadidura, puede decirse que la inclusión de Saint-Simon en los anales del pensamiento socialista se presta a alguna controversia, pues su contribución teórica aparece frecuentemente trufada por postulados del liberalismo económico clásico. No de manera infundada algunos analistas contemporáneos han dictaminado que el epíteto de socialista que se le asigna a SaintSimon es principalmente tributario de la labor de tergiversación del mensaje de este autor

\footnotetext{
${ }^{47}$ LOMENIE, Louis-Léonard, Galerie des Contemporains illustres...op.cit., pág. 622. También PROUDHON, Joseph, De la justice dans la révolution et dans l'église, T.II, Bruselas y Lepizig, Schnée Libraire Éditeur, 1860, pág. 44. Igualmente, Émile Levasseur, Histoire des classes ouvrières en France depuis 1789 jusqu'à nos jours, T.II, Librairie Hachette, París, 1867, pág. 14 y GARNIER, Joseph, Traité D'Économie Politique...op.cit., pág. 488.

${ }^{48}$ Loménie, Louis-Léonard, Galerie des Contemporains illustres...op.cit., pág., 616. La cita original de Saint-Simon la encontramos en Le Producteur: journal philosophique de l'industríe, des sciences et de beaux arts, T. IV., París, Galerie de Bossange Père, 1826, págs. 105 y 106.

${ }^{49}$ LOMENIE, Louis-Léonard, Galerie des Contemporains illustres...op.cit., pág., 616.
} 
efectuada por algunos de sus seguidores ${ }^{50}$. Sea como fuere, autoría de Saint-Simon o de sus discípulos, lo cierto es que el principio cada uno según su capacidad, a cada capacidad según sus obras adquirió un relativo grado de popularidad ${ }^{51}$. Ese es el dato que aquí más nos interesa, ya que partiendo del mismo podría entenderse, quizás, la concreta redacción adquirida por el aforismo que nosotros aquí analizamos. Quizás — y esto es una mera conjetura propia - este último surgió para ser confrontado con las propuestas distributivas de los saintsimonianos. Quizás se quiso, mediante el paralelismo semántico, expresar de manera más explícita la antinomia que subyacía entre estas distintas proposiciones.

Esta hipótesis se refuerza si constatamos que tampoco Fourier, en lo que hemos comprobado, formuló un lema que rezase "a cada uno según su capital, su trabajo y su capacidad", y sin embargo esta fue una expresión que pululó como consigna de su escuela $^{52}$. Ciertamente, en esa frase se ve reflejado el criterio que Fourier propuso para la repartición de la producción obtenida en el régimen del falansterio ${ }^{53}$, pero no llegó a emplear aquella concreta literalidad. Según nuestro planteamiento, aquella expresión pudo ser resultado, nuevamente, de una reformulación tendente a condensar aforisticamente, y mediante construcciones sintácticas afines, las distintas posturas que concurrían en el debate que analizamos en este epígrafe.

Como hemos afirmado, en este debate fue Louis Blanc el principal apologista del criterio distributivo que nosotros estudiamos. Por ello, aunque hayamos concluido que se arrogó indebidamente la originalidad del referido aforismo $-\mathrm{y}$ aclaramos ahora que no le

50 “[E]l término «socialista» es aplicado a Saint-Simon con mucha generosidad. Si bien hay que reconocer que sus ideas influenciaron a los posteriores [...]. Efectivamente, se suele sostener que fueron varios miembros de su escuela los que, con diferentes reformulaciones, contribuyeron a la redefinición socialista de las teorías de Saint-Simon". Valero, Juan: "Los precursores del socialismo", Tiempo de Historia, núm. 86 (1982), págs. 14-33, pág. 17.

${ }^{51}$ Este principio estaría presente en las publicaciones de los autores afines al saint-simonismo entre la década de 1820 y de 1830. C.fr. Bovens, Luc y LuTZ, Adrien, "From Each according to Ability...op.cit., pág. 241. Hemos localizado, incluso, una obra monográfica de aquella época en la que se trata este principio: PALMIERI DI MICCICHE, Michel, A chacun selon sa capacité, à chaque capacité selon ses oeuvres, París, Chez Dent, 1831.

52 Vid. Proudhon, Joseph, Euvres complètes de P.-J. Proudhon...op.cit., págs. 97 a 99; GARNIER, Joseph, Traité D'Économie Politique Sociale...op.cit., pág. 488.

${ }^{53}$ Concretamente, cuando Fourier se refiere a los objetivos que debería alcanzar el su proyecto falasnterario, indicará que este debe tener "la propiedad de hacer el trabajo atractivo; triplicar el producto real de la industria; reconciliar las pretensiones, dividiéndolas en proporción con las tres facultades de la industria, capital, trabajo y talento". FOURIER, Charles: Traité de l'Association domestique-agricole, trabajamos con la versión incluida en Oeuvres complètes, Paris, Société pour la propagation et pour la réalisaton de la theorie de Fourier, 1843 (orig. 1822 bajo el título, Théorie de L'unité universelle), pág. 37. 
imputamos con ello ningún fraude intelectual ${ }^{54}$ - , debe atribuírsele no obstante un importante protagonismo en su divulgación ${ }^{55}$, al vindicar, con insistencia y un notable calado argumentativo, la mejor legitimidad de este criterio de reparto. Veamos los términos en los que Blanc participó en esa discusión.

Desde las primeras ediciones de la Organización del Trabajo Louis Blanc reprobará la proposición distributiva de los saintsimonianos. Así se lee en la que se publicó en $1841^{56}$ :

"En la doctrina saint-simoniana, el problema de la distribución de beneficios se resuelve con esta famosa fórmula: a cada uno según su capacidad; a cada capacidad según sus obras. En nuestro proyecto, la desigualdad de aptitud solo se asigna como base para la diferencia de remuneración solo temporalmente y con restricciones significativas. De modo que lo que forma el principio de la moral de Saint Simón es, en nuestro proyecto, solo una concesión necesaria a las ideas que consideramos falsas y sobre las cuales queremos que la educación prevalezca las nociones de "moral superior" 57 .

Será en ediciones más tardías de esta misma obra cuando, como veíamos, Blanc completará esta crítica con la presentación de una regla de distribución alternativa: de cada cual según su capacidad, a cada cual según sus necesidades. La prevalencia de un principio sobre otro la justifica Blanc en el mayor grado de fraternidad que incorporaría la distribución según las necesidades. Debemos ahora reparar en que la efectividad del principio político-jurídico de fraternidad fue un leitmotiv recurrente en la aportación

\footnotetext{
${ }^{54}$ Somos conscientes de que, entre las múltiples críticas que se le han dirigido a la aportación teórica de Blanc, una recurrente es la fatal de originalidad. Así, en el compendio socialista de Droz se dice: "Louis Blanc no es ni un espíritu original ni un verdadero teórico, y debe lo esencial de su doctrina a los socialistas que le precedieron o a los que le son contemporáneos". En A.A.V.V. (dir. DROZ, Jacques): Historia General del Socialismo..., op. cit., p. 383. Nosotros, sin embargo, expresamos nuestras dudas a la hora de determinar si Blanc tomaba la cita de Becker, o si la formuló autónomamente alcanzando una redacción coincidente. Como decíamos ya había precedentes de sentencias muy afines, y el debate al que ahora estamos aludiendo entre las distintas corrientes del socialismo nos hace pensar que Blanc pudo articular por sí mismo el adagio para asimilarla al propuesto por los saintsimonianos. No hemos encontrado por lo demás ningún dato que revele que Blanc fuese conocedor de la obra de Becker. As si en rigor admitimos que este último antecedió a Blanc en la formulación de esta máxima, no tenemos evidencia alguna que revele que Blanc la tomase de aquel.

${ }^{55}$ G.H Cole no asegura que fuese Blanc fuese el verdadero autor de esta máxima, pero sí le reconoce en cualquier caso la responsabilidad en su divulgación: Historia del pensamiento socialista, I: Los precursores, 1789-1850 (trad. Landa, Rubén), Ciudad de México, Fondo de Cultura Económica, 2020 (versión electrónica). Según se le lee: "La otra razón por la que Blanc ocupa un lugar en la historia del pensamiento socialista es que inventó, o al menos popularizó, la divisa "de cada cual según sus capacidades; a cada cual según sus necesidades".

${ }^{56}$ La más remota a la que hemos tenido acceso, sin haber podido localizar la original del año 1839.

${ }^{57}$ Blanc, Louis, L'Organistaion du Travail...op.cit., pág. 117. Esta crítica fue recurrente en la obra de Blanc. Otra más intensa la encontramos en BlANC, Louis, Historia de diez años...op.cit., pág. 161.
} 
teórico-social de Blanc ${ }^{58}$. En su discurso, el valor fraternidad se define como "el principio en virtud del cual los hombres, en lugar de aislarse y disputarse la vida y la fortuna como si fuera una presa, en definitiva, de destrozarse, reúnen sus voluntades y trabajan juntos en una obra común" "59. Su prototipo de orden social idílico será aquel en el que se disuelva el antagonismo de intereses entre clases y en el que la solidaridad se erija en principio rector básico, en sustitución de la competencia y el individualismo que rigen en el orden capitalista $^{60}$. El criterio distributivo pseudosaintsimoniano, por su parte, no edulcora ninguno de estos dos rasgos del capitalismo que serían, en última instancia, la causa del pauperismo en el que se hallaban instaladas las clases laboriosas: 1) No enervaría la competencia, desde el momento en que los operarios obtienen una mayor ganancia por un mayor desempeño, por lo que no es descartable que el afán de lucro los mueva a disputarse el acceso al trabajo. 2) No afecta al individualismo, ya que dicha regla distributiva no incorpora ninguna obligación social — del individuo hacia sus congéneres_-; se trata de una forma de distribución que solo toma en consideración al individuo, a su capacidad y a sus obras.

No debe extrañarnos por tanto que algunos autores del momento vieran en el principio de los saintsimonianos un escaso compromiso transformador. La regla de remuneración según la capacidad y las obras no dejaría así de ser el resultado aplicativo de las leyes capitalistas de oferta y demanda: “¿no es así como suele hacerse cuando los hombres capaces no compiten demasiado? Los salarios de los hombres capaces y trabajadores

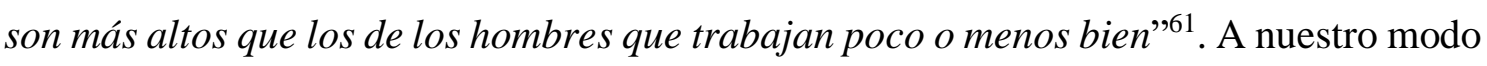
de ver y como breve apostilla, siendo cierto que dicha regla distributiva no subvertía los esquemas de intercambio capitalistas, sí que introducía sobre estos importantes enmiendas. Con su proclamación, los heresiarcas del saintimonismo estaban atacando la legitimidad de la adquisición de bienes por cualquier título ajeno al trabajo propio. Principalmente recusaban la transmisión hereditaria como principal factor de perpetuación del sistema de clases; pero de tal principio también sería dable inferir la reprobación del enriquecimiento a través del trabajo ajeno ${ }^{62}$. Así, afirmaban la teoría

\footnotetext{
${ }^{58}$ Vid. Vigo Serralvo, Francisco, El derecho al trabajo, un primigenio...op.cit., págs. 157 y ss.

${ }^{59}$ Blanc, Louis, Catéchisme des socialistes. París, Au bureau du nouveau Monde, 1849, p. 9.

${ }^{60}$ Como muestra de esto último, vid el extracto un discurso pronunciado en la Comisión de Luxemburgo a los delegados de los patronos franceses el 17 de marzo de 1848 recogido en BLANC, Louis, La Révolution de Février au Luxembourg, París, Michel Lévy Frères, 1849, p. 29.

${ }^{61}$ LOMENIE, Louis-Léonard, Galerie des Contemporains illustres...op.cit., pág., 617.

62 "Los líderes de la religión de Saint-Simon declararon que rechazaban la comunidad de bienes y la distribución equitativa de la propiedad, ya que eran herejías que violaban la primera de las leyes morales e incompatibles con el orden social y la asociación, incluida la desigualdad. es la base y la condición esencial; pero exigieron que se aboliera la herencia, que todos los instrumentos de trabajo, tierra y capital, formando el fondo fragmentado de todas las propiedades particulares, fueran explotados, asociados y
} 
propiedad-trabajo, tan arraigada en la época ${ }^{63}$, pero la llevaban a un grado de realización más puro. Quizás no sería impropio ver en el patrón distributivo de los saintsimonianos una primera formulación del derecho al producto integro del trabajo, otra consigna socialista que posteriormente adquirió una notable presencia ${ }^{64}$.

En cualquiera de los casos, este planteamiento distributivo, el que se le atribuyó apócrifamente a Saint-Simon, si bien y por lo dicho entendemos que procuraba una sincera mejoría en la suerte de las clases laboriosas, no incorporaba ningún rasgo socializante, entendiendo este último apelativo como antagónico del individualismo, como la colaboración mutua entre los distintos sujetos que integran una comunidad. Ahí precisamente, según Blanc, residiría la mayor legitimidad de la particular regla distributiva que él defendió y que nosotros aquí analizamos. Según manifestaba el autor madrileño:

"¡A cada uno según sus obras! Esta ley de distribución es tan falsa, tan obviamente absurda e injusta, que la sociedad se volvería imposible el día que uno tratara de violarla. ¿Es la fórmula para cada uno según sus trabajos, o la fórmula para cada uno según sus necesidades, lo que pone en práctica a la madre que amamanta a su hijo, cuyos trabajos actuales son cero y los trabajos por venir ignorados? ¿Es la fórmula para cada uno según sus obras, o para cada uno según sus necesidades que el hijo que cuida a su viejo padre pone en práctica, sin medir el cuidado que le da, ya sea para presentar trabajos o para trabajos pasados? ¿Es la formula cada uno según sus obras, o a cada uno según sus necesidades que los ojos del alma lean en la puerta de las universidades donde se crían niños, hospitales donde se visten los heridos, hospicios donde uno recoger el viejo tocino, casas donde alimentamos a los locos? ;Oh sociedad consecuente, que duda en aplicar lógica y completamente un principio sin el cual dejarías morir a las personas mayores y a los niños, sin el cual perderías lo que fue y lo que será, ayer y mañana!"65.

Con todo, a pesar de las múltiples y notorias diferencias existentes entre ambos planteamientos, el de reparto según capacidades y obras, o según capacidades y necesidades, se dan entre ellos algunos puntos de comunión. Así, de entrada y según habrá apreciado el lector, tanto el planteamiento de los discípulos de Saint-Simon, como el de

distribuidos jerárquicamente, de modo que cada uno tuviera medios de producción proporcionales a su habilidad y disfrute según sus obras" RENARD, Edouard, Louis Blanc. Sa vie, son oeuvre, Librairie Hachette, 1923, pág. XVIII.

${ }^{63}$ Vid. VIGO SERRALVO, Francisco, El derecho al trabajo, un primigenio y alternativo...op. cit., págs. 63 y ss.

${ }^{64}$ Vid. MENGER, Anton, El derecho al producto íntegro del trabajo (edición y estudio preliminar «derechos sociales y Estado democrático social en Antón Menger» MonEREo PerEZ, José Luis), Granada, Editorial Comares, 2004 (orig. 1886).

${ }^{65}$ Blanc Louis, Historie de la Revolution de 1848, T. II, París, Librairie Internationale, 1870, pág. 258. 
Blanc — prohijado de Morelly y quizás de Cabet y Becker - coinciden en lo relativo a la determinación del grado de implicación del individuo en la actividad productiva: en uno y otro caso se hará según su capacidad. Es decir, en uno y otro caso, el trabajo se concebía como un deber que toda persona debía ejecutar de conformidad con sus aptitudes psicofísicas. Por otro lado, podríamos intuir que la operatividad de cualquiera de estas dos reglas de reparto exige una organización centralizada y planificadora, pues la espontánea y atomizada actuación de los individuos no necesariamente se encaminará a la persecución de estos principios de justicia. Esta es una suposición que admite matices, como veremos más adelante cuando abordemos el planteamiento marxista, aunque sí concluiremos que las propuestas socialistas previas a Marx sí presupusieron la existencia de una normatividad u otros mecanismos institucionales que garantizarían la efectividad de las distintas reglas distributivas ${ }^{66}$. De esta forma, estas proposiciones, también la fourerista que señalábamos más arriba, se oponían a los dogmas liberales, según los cuales la distribución equitativa de las cargas y beneficios de la sociedad solo se conseguiría a partir del libre concurso de voluntades y la espontánea actuación de los agentes que operan en el mercado.

Esto ultimo nos vale para aclarar, antes de cerrar este epígrafe, que si aquí nos hemos centrado en la discusión doctrinal mantenida en el seno del protosocialismo a la hora de determinar las directrices distributivas de la sociedad, debe afirmarse ahora que tal debate fue de contornos más amplios, y que al mismo concurrieron también las posturas liberalizadoras. Esta últimas rechazaban todos los planteamientos socialistas por entender que la colectividad, como ente impersonal, no debía ser dirigida hacia la consecución de un resultado distributivo preestablecido. Acudiendo a uno los pensadores liberales más salientes de la época, Frédéric Bastiat:

“¿Quieren impedirme evaluar por mí mismo la retribución que me corresponde por mis servicios? ¿Quieren obligarme a obrar como a ellos les agrade, y no como a mi me parezca? [...] En el fondo, cada uno de nosotros tiene en este mundo la responsabilidad de proveer mediante su esfuerzo sus necesidades. Así, si una persona nos ahorra un trabajo, nosotros, a nuestra vez, también debemos ahorrarle uno: nos entrega un bien que es el resultado de su esfuerzo; por tanto nosotros debemos obrar con ella de la misma manera. ¿Pero quién debe hace el ajuste? Ya que entre estos mutuos esfuerzos, trabajos y prestaciones debe haber necesariamente un ajuste a fin de llegar a la equidad y la justicia - a menos que queramos estatuir como regla la injusticia, la desigualdad, el azar; o sea, cualquier cosa menos el juicio humano. ¿Quien debe ser, pues, el juez? ¿No es natural que en cada caso particular las necesidades sean juzgadas por los que las

\footnotetext{
${ }^{66}$ Nosotros, movidos por una vocación de concisión, no hemos abordado los distintos mecanismos que se propusieron para llevar la práctica cada uno de estos principios distributivos. Un comentario sobre estos, en los que se afirma la necesidad de establecer instituciones tendentes a desarrollarlos, los encontramos en ANGlasell i SeRrano, Ramón, Compendio de las lecciones de economía....op.cit., págs. 346 y ss.
} 
sienten, los medios para su satisfacción, por los que los buscan, los esfuerzos, por los que los intercambian? O de verdad propone alguien en serio poner en lugar de esta vigilancia general de las personas afectadas una autoridad social - acaso la del propio reformador del mundo - que tendría entonces que fijar las condiciones infinitamente delicadas de los incontables cambios que acaecieran en todos los puntos de la tierra. ¿Es tan difícil de comprender que esto significaría crear el más falible, más universal y más intolerante de los despotismos; uno que tocaría en lo más vivo y se entrometería en todo, pero que sería también, felizmente, el más imposible de todos, comparable sólo al que alguna vez pudo engendrar la mente de un bajá o un mufti? "'67.

\section{El reparto según las capacidades y las necesidades en el horizonte del proyecto comunista}

La vigencia de aquella discusión decimonónica fue, sin embargo, evanescente. No es fácil encontrar referencias a la misma más allá de la década de 1840. A partir de esa fecha apenas hemos detectado alguna vaga alusión al aforismo que estudiamos en la literatura social o política. El siguiente jalón reseñable en el recorrido histórico que aquí bocetamos lo encontraremos ya en la consabida referencia efectuada por Karl Marx en su Crítica al Programa De Gotha y que reproducíamos al comienzo de este estudio. Con todo debe ahora precisarse que, si bien aquella alusión contenida en las glosas al programa del partido obrero alemán es la única cita explícita de este adagio que hemos encontrado en la obra marxista, existe en esta alguna referencia previa, aunque parcial o incompleta, a dicho criterio de reparto. Concretamente, así aparece en La ideología alemana. Crítica de la novísima filosofía alemana en las personas de sus representantes Feuerbach, B. Bauer y Stirner y del socialismo alemán en las de sus diferentes profetas. En esta obra póstuma de Marx y Engels publicada en 1932, aunque escrita entre 1845 y 1846, se leía lo siguiente:

"[U]no de los principios más esenciales del comunismo, por el que se distingue de todo socialismo reaccionario, estriba en la concepción empírica, basada en la naturaleza del hombre, de que las diferencias referentes a la cabeza y a las capacidades intelectuales no condicionan absolutamente ninguna diferencia en cuanto al estómago y a las necesidades físicas; de que, por tanto la tesis falsa, basada en nuestras condiciones actuales, de "a cada cual con arreglo a sus capacidades", debe transformarse, referida al disfrute en sentido estricto, en la tesis de a cada cual con arreglo a la necesidad; de que, dicho en otras palabras, la diferencia en cuanto a las actividades, a los trabajos, no justifica ninguna desigualdad, ningún privilegio en cuanto a la posesión y al disfrute" 68 .

\footnotetext{
${ }^{67}$ Bastiat, Frédéric, "Libertad como Competencia", en Bastiat Selección de Escritos, Atenas Editores Asociados (versión electrónica), págs. 27 y 28.

${ }^{68}$ MARX, Karl y ENGELS, Frederich, La ideología alemana ...op.cit.,, pág. 658.
} 
Se trata, como vemos, de una referencia parcial al criterio distributivo estudiado, ya que solo se alude a la segunda parte del mismo - la distribución de los beneficios según las necesidades, sin mencionar la distribución de las cargas según las capacidades-, sin embargo, le otorgamos una importante valía. A nuestro parecer, demuestra - si es que acaso se pudiera sospechar lo contrario - que la alusión a dicho principio que encontramos en las Crítica al Programa de Gotha no es esporádica; no debería interpretarse como una boutade o un recurso literario. Con dos décadas de antelación a que se publicasen esas líneas, Marx y Engels ya presentaron - aun parcialmente - esta regla de reparto como un principio nomotético del comunismo. De esta forma, a la sazón cuestionaban los dogmas distributivos acogidos y difundidos por buena parte de los socialistas alemanes ${ }^{69}$. El extracto transcrito refuerza, por lo demás, la hipótesis que defendíamos en el apartado anterior y que afirmaba que el principio de reparto que analizamos surgió como respuesta al criterio de asignación por capacidades que propugnaron previamente los saintsimonianos.

Precisamos, de añadidura, que tampoco en esta otra ocasión Marx indicará el referente del que toma esta regla distributiva. Así, no cita a Morelly, Cabet, Becker, Blanc o cualquiera otros de los eventuales artífices de la misma; aunque no por ello, y como decíamos, concluyamos que incurriese en ningún adanismo. Creemos haber demostrado que este lema adquirió una presencia relativamente notable en las discusiones primitivas del socialismo. Debemos intuir, por tanto, que este era conocido entre los doctrinarios de esta corriente de pensamiento y que se acude a él como una proposición en alguna medida ya popularizada, que, si bien cayó en un relativo ostracismo, Marx contribuyó a galvanizar.

Volvamos ahora a la referencia integra a este principio, la que se contiene en la Crítica al Programa de Gotha. Adentrándonos en el contexto discursivo en el que esta se produce, constataremos que se enmarca en una explicación sobre el itinerario a través del cual el proyecto comunista devendría realizable. Como es sabido por quien nos lee, Marx asume la imposibilidad de estatuir de manera inmediata un sistema comunista, en el sentido pleno de esta palabra. Ello es así desde el momento en que el punto de partida es el de una sociedad capitalista, en la que las lógicas del mercado y el intercambio han sido asimiladas por la población como consustanciales a la naturaleza humana. En palabras del padre de El capital:

"lo que aquí se trata no es de una sociedad comunista que se ha desarrollado sobre su propia base, sino, al contrario, de una que acaba de salir precisamente de la sociedad

\footnotetext{
${ }^{69}$ Concretamente, la referencia que acabamos de extractar se inserta en una crítica a los planteamientos de Georg Kuhlmann. Vid. MARX, Karl y ENGELS, Frederich, La ideología alemana ...op.cit., pág. 656 y ss.
} 
capitalista y que, por tanto, presenta todavía en todos sus aspectos, en el económico, en el moral y en el intelectual, el sello de la vieja sociedad de cuya entraña procede" ${ }^{\text {"70. }}$

De esta forma, lo que propone Marx es una transición gradual hacia el comunismo, la cual articula en dos fases. En la primera de ellas, aceptando el arraigo social de los principios del intercambio mercantil, no se propone abolir estos por completo, sino reformularlos, sustituyendo el intercambio de mercancías por el intercambio de trabajo. El nuevo sistema se asimilaría a las reglas de las transacciones del Derecho patrimonial burgués en la medida que se trata de un intercambio de equivalentes, pero varía en cuanto a su contenido, ya que la abolición de la propiedad privada imposibilita cualquier tipo de transferencia de carácter patrimonial. Según lo expresa Marx "bajo las nuevas condiciones nadie puede dar sino su trabajo, y por otra parte, ahora nada puede pasar a ser propiedad del individuo, fuera de los medios individuales de consumo" "71. ¿Cómo se mantiene entonces el principio de equivalencia en el intercambio? A través del intercambio de trabajo: cada individuo recibe de sus semejantes una porción del trabajo —en sentido figurado - proporcional a la desplegada por él mismo. Se altera el contenido de las transacciones pero el principio conmutativo permanece vigente. Es más, en opinión de Marx, de esta forma se consigue una verdadera efectividad de dicha regla de intercambio, en la medida que el régimen de propiedad privada en los medios de producción permitía la explotación obrera — entendida esta en términos marxistas como la enajenación de la plusvalía del trabajo- Bajo el sistema capitalista los operarios no recibían en realidad una compensación equivalente al trabajo ejecutado. En esta primera fase del comunismo, también denominada socialismo, desaparecería ese régimen de explotación y el trabajador obtendría una compensación verdaderamente proporcional a su desempeño.

Siendo esto un fin deseable, que mejoraría notablemente la iniquidad inicial, no llega a ser la más acendrada fórmula de repartición desde el momento en que no todos los individuos ostentan la misma capacidad de trabajo y podrían darse fácilmente una insatisfacción de las necesidades de los sujetos más débiles. Permitiéndonos la cita de Marx:

"unos individuos son superiores, física e intelectualmente a otros y rinden, pues, en el mismo tiempo, más trabajo, o pueden trabajar más tiempo; y el trabajo, para servir de medida, tiene que determinarse en cuanto a duración o intensidad; de otro modo, deja de ser una medida. Este derecho igual es un derecho desigual para trabajo desigual. No reconoce ninguna distinción de clase, porque aquí cada individuo no es más que un trabajador como los demás; pero reconoce, tácitamente, como otros tantos privilegios

\footnotetext{
${ }^{70}$ MARX, Karl, Crítica del programa de Gotha...op.cit.

${ }^{71}$ Ibíd.
} 
naturales, las desiguales aptitudes de los individuos y, por consiguiente, la desigual capacidad de rendimiento. En el fondo es, por tanto, como todo derecho, el derecho de la desigualdad" 72 .

Esta desigualdad material, tributaria de la desproporción natural de aptitudes, será en opinión de Marx una rémora inevitable del sistema capitalista del que se parte, que necesariamente persistirá durante la transición hacia la genuina sociedad comunista. Tal y como él lo expresa:

"estos defectos son inevitables en la primera fase de la sociedad comunista, tal y como brota de la sociedad capitalista después de un largo y doloroso alumbramiento. El derecho no puede ser nunca superior a la estructura económica ni al desarrollo cultural de la sociedad por ella condicionado"73.

Será solo en una ulterior y definitiva fase del comunismo, desembarazada ya de la lógica y las costumbres capitalistas, donde resultaría operativo el verdadero ideal distributivo del comunismo que Marx identifica, ya sabemos, con la regla de cada cual, según sus capacidades; a cada cual según sus necesidades. En este sentido, es curioso constatar como existe cierto paralelismo con el planteamiento de Blanc ${ }^{74}$, quien estimaba que este principio de reparto solo sería operativo después de una fase transitoria previa, en la se aplicase un impío — según este último autor lo calificaba - criterio de reparto igualitario, y durante la cual se superase la lógica subordinadora del capitalismo.

Entre los presupuestos que, según Marx, deberían darse para alcanzar esta segunda y superior fase de la sociedad comunista - vid. supra, extracto inicial de Marx-, estaría el de alcanzar la abundancia de bienes materiales; de ahí que algún autor contemporáneo haya cuestionado que en realidad el principio que analizamos represente para Marx un verdadero criterio de distribución, lo cual solo sería pertinente en un marco de

\footnotetext{
${ }^{72}$ Ibíd.

73 Ibíd.

${ }^{74} \mathrm{Si}$ decimos que este paralelismo nos resulta curioso ello se debe a la desafección que Marx profesó por Blanc y que hizo pública en varias ocasiones. Verbigracia, Karl Marx le dedica despectivamente la frase con la que abre El 18 de brumario de Luis Bonaparte: "Hegel dice en alguna parte que todos los grandes hechos y personajes de la historia universal aparecen, como si dijéramos, dos veces. Pero se olvidó de agregar: una vez como tragedia y la otra como farsa. Caussidière por dantón, Luis Blanc por Robespierre, la Montaña de 1848 a 1851 por la Montaña de 1793 a 1795, el sobrino por el tío. ¡y la misma caricatura en las circunstancias que acompañan a la segunda edición del 18 brumario!". MARX, Karl: El 18 de brumario de Luis Bonaparte, Madrid, Fundación Federico Engels, 2003 (orig. 1852), pág. 10. También Karl Marx se refería a Blanc como un ser "ávido de saber, pero al mismo tiempo lleno de ignorancia”. tomo esta segunda cita de Bravo, Gian Maria, Historia del socialismo, 1789-1848..., op. cit, pág. 135.
} 
insuficiencia o de escasez de recursos ${ }^{75}$. Por otro lado, resultaría necesario también suprimir la división del trabajo, haciendo de este último una actividad placentera y reconfortante para el hombre ${ }^{76}$. Al menos en nuestra opinión, Marx no aclara del todo desde luego no lo hace en estos pasajes - la relación causal entre la reconversión del trabajo en una actividad agradable y la implementación de un sistema de reparto según las necesidades. Pudiera intuirse que de esa forma, mediante la reformulación valorativa del trabajo, se aspira a alcanzar una sociedad armoniosa, no pautada por la rivalidad y el conflicto de intereses: Al ser el trabajo una ocupación placentera, el individuo no se opondría a su participación productiva de conformidad con sus capacidades, siendo esta participación, en última instancia, una labor de colaboración social. La efectividad de este principio se hace así recaer sobre el altruismo humano antes que sobre mecanismos institucionales de coerción. Presupone, de manera asaz filantrópica, que los individuos adoptarán voluntariamente esta forma de reparto cuando se hayan enajenado las formas de explotación burguesas. Recordemos que el desiderátum último del comunismo, tal y como fue definido por Marx, pasaba por la abolición del Estado ${ }^{77} \mathrm{y}$, con este, de todos los mecanismos punitivos que dotan de efectividad a las normas jurídicas ${ }^{78}$. En consecuencia, esta regla de partición, que solo se alcanzaría en la cúspide del comunismo, no contará con el respaldo institucional-jurídico; se sostendrá sobre la voluntad espontánea — no coaccionada — de los individuos. Como atinadamente algún analista ha apreciado, el principio de reparto que analizamos estaría llamado a funcionar en "una sociedad en la que los derechos y la justicia ya no tienen ningún papel que desempeñar"79. Así, mismamente, lo interpretó uno de los promotores empíricos más relevantes del comunismo: Vladímir Ilich Uliánov, más reconocido por su sobrenombre, Lenin:

"El Estado podrá desaparecer por completo cuando la sociedad adopte la regla: De cada uno según su capacidad, a cada uno según sus necesidades, es decir, cuando las personas se hayan acostumbrado tanto a observar las reglas fundamentales de las relaciones sociales y cuando el trabajo se ha vuelto tan productivo que trabajarán voluntariamente de acuerdo con su capacidad. El estrecho horizonte de la ley burguesa, que obliga a uno a calcular con la crueldad de un Shylock si uno no ha trabajado media hora más que nadie: este estrecho horizonte se quedará atrás. Entonces no habrá

\footnotetext{
${ }^{75}$ Así, en opinión de Will Kymlicka: "No es un principio bajo el cual se distribuyen los recursos escasos, sino simplemente una descripción de lo que sucede bajo el comunismo: las personas toman lo que necesitan del stock de recursos abundantes". KYMLICKA, Will, Contemporary Political Philosophy, Nueva York, Oxford University Press, 2002, pág. 187.

${ }^{76}$ Cfr. ut supra, extracto inicial de Marx, en la cita enumerada a pía de página con el 3.

77 Vid., TARA, Vasile y MÜLLER MonTIEL, Ángela, "La Evolución De La Idea De Desaparición Del Estado En La Teoría Marxista", en Revista Mexicana de Sociología, vol. 24, núm. 1, 1962, págs. 75 a 86.

${ }^{78}$ FURNER James, Marx on Capitalism...op.cit., pág. 364.

${ }^{79}$ ELSTER, Jhon, An Introduction to Karl Marx, Cambridge, Cambridge University Press, 1986 pág. 94. En idéntico sentido: Huids, Peter, Marx's Concept of the Alternative to Capitalism, Leidne/Bostón, Brill, 2012, Pág. 202.
} 
necesidad de que la sociedad, al distribuir los productos, regule la cantidad que recibirá cada uno; cada uno tomará libremente según sus necesidades" $" 80$.

Es curioso apreciar en este extracto cómo, en opinión de Lenin, la aplicación del principio distributivo que venimos analizando y la desaparición del Estado vendrían de la mano, siendo estos dos logros las señas que anunciarían la culminación del proyecto comunista. La consumación de este nos arroja a una sociedad anárquica —en el sentido político más ortodoxo de la palabra - en el que las justas reglas se sostienen sobre la libre actuación de los sujetos que componen la sociedad. Desde esta inteligencia, vemos como Lenin aunque siguiendo de cerca a Marx - presupone que la justicia distributiva es una inclinación natural o innata del ser humano, que solo se ve corrompida bajo el régimen capitalista.

En otro orden de cosas, es relevante constatar cómo Lenin prohíja también el planteamiento de Marx en lo que se refiere a la forma bifásica en la que el ideal comunista debería materializarse. El itinerario hacia ese objetivo requeriría de una fase de transición en la que sería admisible un reparto conforme al trabajo ejecutado. Este criterio sería en todo caso más legítimo que el garantizado por el régimen capitalista, en el que se produce una alienación del valor del trabajo generado por el operario, pero solo se contempla como una medida coyuntural, instrumental para derrocar sistema burgués de propiedad privada y promover las condiciones optimas para la viabilidad del comunismo. Superada esa ineludible fase de transición, debe aspirarse a alcanzar el verdadero ideal comunista de distribución según las capacidades y necesidades de cada individuo. En palabras del revolucionario bolchevique:

"La primera fase del comunismo, por lo tanto, todavía no puede proporcionar justicia e igualdad; las diferencias, y las diferencias injustas, en la riqueza aún persistirán, pero la explotación del hombre por el hombre se habrá vuelto imposible porque será imposible tomar los medios de producción (las fábricas, las máquinas, la tierra, etc.) y hacerlos propiedad privada. Al aplastar las vagas frases pequeño burguesas de Lassalle sobre "igualdad" y "justicia" en general, Marx muestra el curso del desarrollo de la sociedad comunista, que se ve obligada a abolir al principio solo la "injusticia" de los medios de producción incautados por los individuos y que no puede eliminar de inmediato la otra injusticia, que consiste en la distribución de bienes de consumo "de acuerdo con la cantidad de trabajo realizado" (y no de acuerdo con las necesidades)"

80 ILICH Ulí́NOV, Vladímir, The State and Revolution. Versión electrónica accesible en https://www.marxists.org/archive/lenin/works/1917/staterev/ch05.htm\#s3, (última visita el 3 de agosto de 2020).

${ }^{81}$ LENIN, Vladimir, The State and Revolution...op.cit. En sentido similar, Trotsky, Leon, La revolución traicionada.

Versión

electrónica accesible

en 
¿Encontró este planteamiento algún reflejo empírico? Pues, si acudimos a los textos jurídico-políticos del comunismo, responderíamos de manera ambivalente: sí que se codificaron las reglas distributivas de la primera fase del comunismo - la que venimos denominado de transición o socialismo-, pero no se acogieron las propias de esa segunda y superior fase en la que el reparto de las cargas y beneficios de la sociedad se haría según las respectivas capacidades y necesidades de cada individuo. Veamos en este sentido el artículo 12 de la Constitución soviética de 1936 — insertado en capítulo primero, sobre la organización social_- En este precepto, tras imponer la obligación del trabajo invocando literalmente el mandato paulino "el que no trabaja, no come"-, afirma lo siguiente: "En la URSS se cumple el principio del socialismo: De cada uno, según su capacidad; a cada uno, según su trabajo".

Como puede constatarse, el criterio de participación en la vida productiva se corresponde con el propuesto por Marx para la primera fase del comunismo, manteniendo la lógica del intercambio de equivalentes que se hereda de la sociedad capitalista. Esta opción constituyente del régimen soviético —imitada en otros países que abrazaron el comunismo $^{82}$ - supone así una persecución parcial del genuino ideal comunista, el cual no se menciona en la Carta Magna, ni siquiera incorporándolo como objetivo programático. Esta omisión, que perduró en el tiempo, excitó la reprobación de alguno de los referentes intelectuales de la Unión Soviética, como la del malhadado Leon Trotsky. Se le lee a este último comentando el precepto constitucional que hemos reproducido:

"Esta fórmula inconsistente, por no decir vacía de significado, que por inverosímil que parezca pasó de los discursos y de los artículos al cuidadosamente estudiado texto de una ley fundamental, atestigua, más que incapacidad teórica total de los legisladores, lo que hay de mentira en la nueva Constitución [...] En vez de reconocer francamente que estas normas burguesas del trabajo y del reparto predominan en la URSS, los autores de la Constitución, dividiendo en dos el principio comunista, dejan para un porvenir indeterminado la aplicación de la segunda proposición y declaran que la primera está realizada, añadiéndole mecánicamente la norma capitalista del trabajo a destajo y haciendo de todo el "principio del socialismo". iY sobre esta falsificación erigen el edificio de la Constitución!"»3.

https://www.marxists.org/espanol/trotsky/1936/rt/10.htm\#seg\%201 (último acceso el día 3 de agosto de 2020).

${ }^{82}$ A modo de ejemplo, limitándonos a dos textos constitucionales vigentes, este principio, "de cada cual según su capacidad, a cada cual según su trabajo", se encuentra recogido con tal literalidad en el art. 65 de la actual Constitución de la República de Cuba y en el art. 6 de la Constitución de la República Popular China de 1982.

${ }^{83}$ En sentido similar, Leon Trotsky, La revolución traicionada...op.cit. 
En contra de esta postura, y en defensa del constituyente soviético, podría aducirse que la Carta Magna fue fiel al itinerario señalado por Marx, que aquella solo estaba articulando los postulados de la fase transitoria, necesaria para la realización del genuino ideal comunista, y ello a la espera de que acontecieran las circunstancias fácticas que hacían este último realizable. De hecho, según veíamos más arriba, la efectividad del verdadero principio retributivo del comunismo no requería de ningún soporte normativo y presuponía la supresión de las instituciones estatales ${ }^{84}$, inclusive, de manera obvia, la Constitución. De esta forma, la crítica de Trtosky no nos parece coherente con los fundamentos dogmáticos del comunismo tal y cómo fueron expuestos por Marx. No decimos que estos último sean verosímiles - tampoco lo contrario-, pero sí que la opción constituyente de la URSS se adecúa a los mismos y que el genuino ideal distributivo del comunismo no podría tener encaje en un instrumento normativo de ese tipo. Cuestión distinta, en la que ya no entramos, es la relativa a la vocación de interinidad que debería caracterizar el principio acogido por la Constitución soviética. El texto, desde luego no anuncia ese rasgo de transitoriedad a lo largo de todo su articulado, ni siquiera lo insinúa. Sin embargo, en otros textos que podríamos denominar cuasi institucionales, sí que se alude al carácter eventual con el que se acogen esas normas de reparto, sin que su proclamación implique la renuncia al propósito de alcanzar el verdadero ideal comunista. Así lo manifestaba Joseph Stalin en una de las contribuciones teóricas que se le atribuyen:

\begin{abstract}
"solamente cuando todas estas condiciones previas, tomadas en su conjunto, hayan sido realizadas, podemos esperar que a los ojos de los miembros de la sociedad, el trabajo haya dejado de ser una servidumbre para convertirse en «la primera necesidad de la existencia» (Marx); que «el trabajo en lugar de ser una carga será un placer» (Engels); que la propiedad social sea considerada por todos los miembros de la sociedad como la base inmutable e intangible de la existencia de ella. Solamente cuando todas estas condiciones previas, tomadas en su conjunto, hayan sido realizadas, se podrá pasar de la fórmula socialista «de cada cual según sus capacidades a cada cual según su trabajo», a la fórmula comunista, "de cada cual según su capacidad, a cada cual según sus necesidades»"
\end{abstract}

Huelga aclarar que esas circunstancias fácticas nunca llegaron a materializarse durante toda la vigencia del régimen soviético y que, por tanto, la transición hacia ese ideal de reparto jamás llegó a consumarse. Así se expensaba Leonid I. Brezhnev, líder del politburó entre 1964 y 1982, en un discurso sobre el proyecto de Constitución del año 1977:

\footnotetext{
${ }^{84}$ Vid. Busky, Donlad, F., Communism in History and Theory: From Utopian socialism to the Soviet Union, Vol. 3, Connecticut, Preager, 2002, pág. 122

${ }^{85}$ STALIN, Joseph: Los problemas económicos del socialismo en la URSS, 1952. Tomo la cita de Elejabeitia, Carmen, Liberalismo, marxismo y feminismo, Barcelona, Anthropos, 1987, pág. 166.
} 
"Algunas propuestas se adelantan evidentemente, olvidan que la nueva Constitución es la Ley Fundamental del Estado del socialismo desarrollado, y no del comunismo. En nuestro país rige el principio socialista: De cada uno, según su capacidad; a cada uno, según su trabajo. No es posible, dado el nivel actual del desarrollo económico y del grado de conciencia de los hombres, saltar a través de este principio. Por ello, no pueden ser aceptadas las propuestas, por ejemplo, de implantar salarios y pensiones iguales para todos o de fijar su cuantía exclusivamente en base a la antigüedad laboral, sin tener en cuenta la cualificación de los trabajadores y la calidad de su trabajo" $"$.

En consecuencia, en mérito de lo que hemos expuesto en este apartado, podríamos concluir que el proyecto comunista, con las normas distributivas que dogmáticamente lo definen, no ha encontrado históricamente aplicación empírica. Con ello en modo alguno juzgamos negativamente esta corriente política -el compromiso inicial de equidistancia ideológica trataremos de mantenerlo hasta el final- ni cuestionamos su factibilidad. Rehusando adrede aquí cualquier pronunciamiento sobre ello, la idea de cierre que queremos conservar es que, para los promotores intelectuales y empíricos del comunismo, el principio que aquí analizamos constituyó el fin último de este proyecto político, la hipóstasis de su realización plena. La no aplicación de dicho principio debería llevarnos a rechazar, por tanto, que hayamos conocido hasta hoy una prístina o completa implementación de este sistema político.

\section{Sobre la vigencia actual de esta propuesta distributiva}

Antes de cerrar nos preguntaremos por la presencia actual del aforismo que analizamos y el patrón de reparto que en él se describe; tanto a nivel empírico, como a nivel teórico o doctrinal.

Con respecto al primero de estos niveles, lo que nos cuestionamos es la incidencia que tiene esta regla de reparto en la operatividad y el diseño político-jurídico del Estado social que nos es coetáneo. Intuitivamente, a través de la mera observación, descartaríamos que la acción distributiva del Estado social se haya articulado, ni siquiera intencionalmente, conforme los parámetros de capacidad y necesidad. Y ello desde el momento en que la mayoría de las asignaciones de las cargas y beneficios del proceso productivo se efectúan en el tráfico privado, conforme al principio del intercambio de equivalentes propio del orden capitalista — si bien con alguna injerencia estatal que, en ámbitos localizados,

\footnotetext{
${ }^{86}$ BREZHNEV, Leonid I., "Acerca del proyecto de Constitución (Ley Fundamental) de la Unión de Repúblicas Socialistas Soviéticas y de los resultados del debate de todo el pueblo. Discurso pronunciado el 4 de octubre de 1977, en la Séptima Sesión, extraordinaria, del Soviet Supremo de la URSS, novena legislatura", en Anuario URSS '78, Agencia de Prensa Novosti, Moscú, 1978, págs. 22-28. Accesible en https://www.marxists.org/espanol/brezhnev/1977/octubre/04.htm, (último acceso el día 22 de julio de 2020).
} 
restringe la libertad de los agentes contratantes-. Sí que podríamos encontrar algún débil reflejo del reparto por capacidades en el sistema tributario progresivo; uno de los principales rasgos distintivos del Estado social que impone una contribución según las capacidades de cada uno de los individuos de la sociedad. No obstante, esa progresividad tributaria toma en consideración únicamente los medios patrimoniales, y no exige una participación productiva mayor de los sujetos con capacidades naturales para el trabajo más cualificadas. Además, la distribución de la recaudación así obtenida no se efectúa prioritariamente en función de las necesidades de los individuos. Solo una pequeña cuota de la protección social dispensada por el Estado se atribuye según las necesidades de cada cual. El criterio de reparto preferente es el formal-igualitario - por ejemplo, en la dotación de infraestructuras públicas, seguridad u otros servicios comunales-, o el aseguraticio o profesional-contributivo, que, ante la actualización de determinadas contingencias, otorga rentas proporcionales a la participación del sujeto en el proceso productivo - lo que no deja de asemejarse al criterio de asignación según las obras que propusieron algunos seguidores de Saint-Simon-. Según lo vemos, deberíamos concluir que en la estructuración del Estado social y su acción distributiva no encontramos un criterio uniforme. Ninguna de las distintas opciones de reparto que aquí se han señalado encontraría una aplicación prístina y generalizada. Quizás resulte más acertado concluir, como lo hace Aguiar González, que en cada una de las distintas esferas del Estado social predominan criterios autónomos y diferenciados. Según constata este último autor "los bienes que se precisan para tener una buena salud se distribuyen según el principio «a cada cual según sus necesidades»; los premios y castigos se distribuyen según el mérito; la educación superior según el talento; la ciudadanía según las tradiciones de la comunidad y la riqueza según la habilidad y la suerte que se tenga en el mercado"87.

Dicho lo anterior, aunque hayamos descartado que el principio que analizamos actúe hoy - o haya actuado en el pasado - como criterio de repartición predominante en una sociedad extensa, no es menos cierto que puede apreciarse su aplicación empírica en las relaciones sociales que se producen dentro de grupos domésticos o pequeñas comunidades $^{88}$, entre cuyos miembros perviven lazos de solidaridad o fraternidad que los llevan hacia esta forma de cooperación. En este ámbito, inclusive el Derecho positivo impone que la responsabilidad de sostenimiento entre deudos se module conforme los

\footnotetext{
${ }^{87}$ Aguiar GonZÁLEZ, Fernando, "Justicia distributiva. Eunomía", en Revista en Cultura de la Legalidad, vol. 17/2019, págs. 207-219, pág. 216.

${ }^{88}$ En palabras del sociólogo Max Weber: "El principio del comunismo doméstico, sin "asignaciones" individuales, sino que el individuo contribuye según sus fuerzas y goza según sus necesidades (en tanto como alcanzan los bienes), perdura todavía hoy como la característica más esencial de la comunidad doméstica de nuestra "familia", claro que casi siempre como un residuo limitado al consumo doméstico". Weber, Max, Economía y sociedad (trad. Medina Echavarria, José et al.), Madrid, Fondo de Cultura Económica, 1964 (orig. 1922), pág. 292.
} 
parámetros de capacidad y necesidad ${ }^{89}$. Recordemos, de pasada, que algunos autores como Blanc, al reivindicar la implementación de esta regla distributiva, pretendían con ella hacer efectivo el principio político-jurídico de fraternidad, el cual había sido desatendido desde que se inscribió en el tríptico revolucionario de 1789. Para ello, se tomaba como referente los comportamientos fraternales propios de las relaciones intrafamiliares, identificando los criterios de distribución que en estas se daban para tratar de extrapolarlos, con las debidas alteraciones, al nivel macro o estatal. Ello nos mueve a exponer una apreciación — un truismo, en realidad - y sostener que la equidad del principio de distribución según las capacidades y necesidades está, en cierta medida, interiorizada por la ciudadanía, pero restringida al circulo de congéneres más cercanos. Existe así un diferente baremo para determinar la participación justa de los individuos en las cargas y beneficios de la sociedad en función del grado de parentesco o afinidad ostentado.

Cambiando ahora de marco, nos preguntamos también sobre la eventual pervivencia de este principio en el debate político-filosófico contemporáneo. Sobre ello, se ha dicho que esta regla de reparto ha acaparado un escaso interés por parte de los intelectuales. Así, y según aprecia el profesor Gilabert, aunque dicho principio "es posiblemente el corazón ético del socialismo, sorprendentemente, casi no ha recibido atención de los filósofos políticos" $"$. Compartiendo en parte esta apreciación, estimamos no obstante que esta desatención es relativa, y que todavía hoy puede decirse que el meritado principio es tomado en consideración por la filosofía-política, sobre todo en el marco de la sempiterna e insoluta disputa sobre la repartición equitativa de los beneficios y las cargas de la sociedad $^{91}$.

Las distintas posiciones que mantienen vivo este debate se han relacionado como sigue: "a cada cual la misma cosa, a cada cual según sus méritos, a cada cual según sus obras, a cada cual según sus necesidades, a cada cual según su posición o a cada cual según lo que la ley le atribuye"92.

\footnotetext{
${ }^{89}$ Así, como botón de muestra, el art. 146 del Código Civil español determina que "La cuantía de los alimentos será proporcionada al caudal o medios de quien los da y a las necesidades de quien los recibe". ${ }^{90}$ GILABERT, Pablo, "The socialist principle from each according to their abilities, to each according to their needs", Journal of social philosophy, vol. 46, núm. 2, 2015, págs. 197-225, pág. 197.

${ }^{91} \mathrm{Si}$ decimos sempiterna es porque la determinación de la forma más equitativa para operar la partición de los bienes sociales es una cuestión presente en el análisis filosófico desde la Antigüedad. Aunque no podemos detenernos en este asunto, baste señalar las célebres de inquisiciones de Aristóteles sobre la justicia conmutativa y distributiva que se contienen en Etica Nicomáquea, Madrid, Editorial Gredos, 2010, págs. 144 y ss.

92 Vidal Molina, Paula F., "La teoría de la justicia social en Rawls", Polis, núm. 23/2009. Accesible en http://journals.openedition.org/polis/1868 (último acceso el 12 de julio de 2020).
} 
De todas estas alternativas distributivas, centrándonos en la que motiva en nuestro estudio, si bien esta cuenta con una adscripción minoritaria, existen en la actualidad pensadores que postulan su mejor legitimidad ${ }^{93}$. Según se ha expresado por alguno de los más destacados exponentes de esta posición filosófica, tal principio "sigue siendo un ideal moral convincente, superior a la aceptación resignada, complaciente o entusiasta de la desigualdad económica que ofrecen los defensores del capitalismo convencional y por muchas versiones del liberalismo"94. Entre los heterogéneos argumentos que se invocan para sostener la pertinencia de esta regla distributiva, el más recurrente será el de la mayor equidad sustantiva que promovería su aplicación, afirmándose que la implementación de dicho principio resulta "crucial para la realización de la justicia igualitaria"95. Más concretamente, se dice que este principio distributivo promueve un igualitarismo del bienestar $^{96}$, equiparando, a través de una distribución irregular, el nivel de satisfacción colectiva de las necesidades y el esfuerzo productivo. Obviamente, ese argumento solo resultará convincente si se parte de una predilección por el igualitarismo, concibiendo este como un fin social conspicuo ${ }^{97}$, lo cual no es desde luego una posición generalizada ni axiomática. Otros alegatos a favor de este principio podrían ser el desarrollo de un sentido de responsabilidad para con el prójimo o la supresión de la competitividad propia del sistema capitalista y las perniciosas derivadas que de esta se siguen ${ }^{98}$.

En un número superior al de sus partidarios, la idea distributiva a la que estamos aludiendo encuentra también sus detractores. Entre las recusaciones más frecuentes, la más iterativa será la que reprocha la falta de concreción que esta fórmula presenta, sobre todo en lo relativo al concepto de necesidad y si este debe ser contemplado en sentido lato o estrecho ${ }^{99}$. Lo primero, nos dejaría un concepto de necesidad altamente volátil y cargado de subjetividad, que haría imposible constatar el éxito en la realización de este ideal distributivo. Lo segundo, nos arrojaría a un estilo de vida frugal, poco sugerente para gran parte de la ciudadanía. Obviamente, también se han expresado recelos sobre la predisposición del ser humano para ejercitar sus capacidades productivas altruistamente

\footnotetext{
${ }^{93}$ ElSTER, Jon: "Exploitation, Freedom, and Justice”, en A.A.V.V. (Eds. J. R. Pennock y J. W. Chapman), Marxism, Nueva York, New York University Press, 1983, págs. 277-304; CoHEN, Gerald A., Karl Marx's Theory of History: A Defense, Princeton, Princeton University Press, 1978. Este mismo autor en If You're an Egalitarian, How Come You're So Rich?, Massachusetts, Harvard University Press, 2000.

94 CARENS, Joseph H., "An interpretation and defense of the socialist principle of distribution", Social Philosophy and Policy, núm. 20/2003, págs. 145-177, pág. 145.

95 Ibíd., pág. 177.

${ }^{96}$ ELSTER, Jon, An Introduction to Karl Marx, Cambridge, Cambridge University Press, 1986, pág. 100.

${ }^{97}$ CARENS, Joseph H., “An interpretation and defense of the socialist...op. cit., pág. 177.

${ }^{98}$ Para una relación más exhaustiva de los argumentos contemporáneo favorables a esta regla vid. Gilabert, Pablo, "The socialist principle from each according... op.cit., págs. 198 a 203.

${ }^{99}$ KYMLicKA, Will, Contemporary Political Philosophy... op.cit., pág. 187.
} 
con el propósito de procurar el bienestar de sus semejantes ${ }^{100}$. Se ha alegado, además, la eventualidad de una disociación entre la producción y las necesidades de una sociedad: si el individuo no encuentra ningún estímulo para dirigir su actividad profesional hacía la satisfacción de las necesidades emergentes - como ocurre en el libre mercado a través de la expectativa de lucro- es previsible, según se alega, la existencia de necesidades insatisfechas. Finalmente, y en contra del argumento igualitarista que con mayor intensidad postulan los defensores de esta norma de reparto, se ha dicho que "desde un punto de vista igualitario y bienestarista, el problema con el ideal de poner la economía en conformidad con esta norma es que, las personas con la misma capacidad tienen diferentes grados de gusto o aversión por el trabajo" ".101. Según este último razonamiento, dos sujetos que ostenten un nivel equiparable de capacidades pueden percibir un distinto grado de sacrificio en la realización de la misma tarea, produciéndose así una desigualdad en el grado de bienestar experimentado por cada uno de ellos.

En cualquiera de los casos, admitimos que los juicios a favor y en contra de este principio se exponen aquí de manera muy superficial y con una modesta vocación enunciativa ${ }^{102}$. No es el propósito de este estudio ahondar en este debate, que presenta magnitudes ciertamente amplias. Por supuesto, tampoco nos decantaremos por ninguna de las posiciones que concurren al mismo - lo cual sería una opción que estaría irremediablemente condicionada por preferencias ideológicas subjetivas-. Si nos referimos en estas líneas finales a la discusión que se mantiene hoy sobre este principio distributivo es con el único propósito de afirmar su pervivencia contemporánea, para así traer hasta nuestros días la evolución diacrónica que aun de manera incompleta — solo el que leyere valorará con cuán grado de incompletitud - hemos pretendido describir en este estudio.

\section{Epítome}

Para clausurar este estudio incorporaremos una breve recapitulación de las que, a nuestro modo de ver, serían las principales ideas tratadas en el mismo. Así, y según el orden en el que han sido expuestas, diríamos:

\footnotetext{
${ }^{100}$ GILABERT, Pablo, "The socialist principle from each according to their...op.cit., pág. 205.

${ }^{101}$ RICHARD, Arneson, "Is Work Special? Justice and the Distribution of Employment" en A.A.V.V., (editor Kory P. Schaff) Philosophy and the Problems of Work: A Reader, Bostón, Rowman \& Littlefield Publishers, págs. 562-607, pág. 586.

102 Para un recorrido más exhaustivo por las distintas posturas que concurren al contemporáneo sobre esta regla distributiva remitimos a KYMLICKA, Will, Contemporary Political Philosophy...op.cit., págs. 172 y ss.
} 
- Que existe disparidad de criterios a la hora de determinar la paternidad intelectual del aforismo de cada cual según sus capacidades, a cada cual según sus necesidades. Entre los pensadores a los que se les ha atribuido su autoría, estarían: Morelly, Babeuf, Blanc, Cabet, Becker y, con frecuencia aunque con escaso rigor, Marx.

- Según nuestro escrutinio, concluiríamos que fue Morelly el primero en defender la idea sustantiva de reparto que subyace en ese lema. Luego, el planteamiento morelliano fue sintetizado en consignas que se asemejan mucho a la formulación con la que a la postre sería popularizado. Sentencias de este tipo podemos encontrar en Cabet, año 1840, o en el analista político François Villegardelle, año 1841.

- Dicho lo anterior, si somos especialmente celosos en los aspectos semánticos, concluiríamos que el primer autor que enunció de manera expresa el citado aforismo, en su literalidad más célebre, fue el socialista alemán August Becker, en el año 1844.

- Desde sus primeras invocaciones esta particular regla de reparto se asoció al comunismo. Así, Cabet lo presentó como uno de los principios rectores de este proyecto político y después Becker lo elevó al rango de principio fundamental de este.

- A mediados del siglo XIX este lema adquirió cierta popularidad, en buena medida por la confrontación de posturas que se dio en el seno del protosocialismo francés en lo concerniente a las normas que deberían regir la distribución de las cargas y beneficios de la sociedad. En este debate, el principal defensor del criterio de asignación que analizamos fue Louis Blanc, que lo presentó como una opción meliorativa de las postuladas por la escuela saintsimoniana — distribución según las capacidades y las obras - y la escuela fourerista — retribución según el capital, el trabajo y la capacidad-.

- Con posterioridad este lema sería invocado por Marx en su Crítica al Programa de Gotha, presentándolo como el fin último al que aspira la sociedad comunista. Si bien y por lo dicho tal pronunciamiento careció de originalidad, fue sin embargo decisivo en la notoriedad histórica adquirida por este apotegma.

- Según la tesis marxista, este genuino ideal distributivo del comunismo solo sería alcanzable tras una fase transitoria previa - que podemos denominar socialismo - en la que se produciría una retribución en función del trabajo desplegado por cada individuo. Esta opción, que no sería del todo equitativa, se contempla como criterio provisional en tanto que se removiesen las trabas fácticas que impedían la realización del más legítimo reparto según las capacidades y las necesidades de cada cual. 
- Los proyectos políticos empíricos que aspiraron al desarrollo del comunismo hemos focalizado nuestra atención en el caso de la U.R.R.S. - codificaron en sus respectivos textos constitucionales el criterio de distribución propio de la fase de transición hacia el comunismo. La realización del reparto según las capacidades y necesidades quedó como un desiderátum insatisfecho, según se justificó, por la inexistencia de las condiciones fácticas necesarias para su viabilidad.

- Hoy este principio ha perdido buena parte del protagonismo que ostentó en otro tiempo, aunque mantiene una pervivencia marginal. En el terreno de lo empírico tal criterio de distribución opera en las relaciones intrafamilaires o en las pequeñas comunidades unidas por lazos de cercanía. En el ámbito de lo teórico o lo doctrinal, encontramos referencias al mismo en la insoluta discusión filosófico-política sobre el reparto de los beneficios y cargas de la sociedad; existiendo autores que todavía en la actualidad lo defienden como la forma más legítima de operar tal reparto y descartan que su aplicación sea necesariamente utópica.

\section{Bibliografía}

A.A.V.V. (Dir. Alain Renaut), Leçons de la philosophie, París, Odile Jacob, 2008, libro electrónico.

A.A.V.V. (Dir. Droz, Jacques), Historia general del socialismo. De los orígenes a 1875, Barcelona, Destino.

A.A.V.V. (Edits. Gary L. Anderson, Kathryn G. Herr), Encyclopedia of Activism and Social Justice, Londres, SAGE Publications, 2007.

A.A.V.V. (Edit. William D.P. Bliss), The New Encyclopedia of Social Reform, Including All Social-Reform Movements and Activities, and the Economic, Industrial, and Sociological Facts and Statistics of All Countries and All Social Subjects, Nueva York, Funk and Wagnalls Co, 1908.

ADAMS, Francis (seudónimo de Cabet, Etienne). Voyage et aventures de Lord Villiam Carisdall en Icarie, T. II, Paris, Hyppolyte Souverain, 1840.

AguiAR GonZÁLEZ, Fernando, "Justicia distributiva. Eunomía”, en Revista en Cultura de la Legalidad, vol. 17/2019, págs. 207-219.

Anglasell i SerRano, Ramón, Compendio de las lecciones de economía política dadas en la Universidad de Barcelona, Barcelona, Imprenta Politécnica de Tomás Gochs, 1858. 
ANÓNIMo, Doctrine de Saint-Simon, Exposition, Bruselas, Louis Hauman et Compagnie, 1829.

ARocena, Rodrigo, La crisis del socialismo de estado y más allá, Montevideo, Ediciones Tricle, 1991.

ARIstóteles, Etica Nicomáquea, Madrid, Editorial Gredos, 2010.

ARNESON, Richard, "Is Work Special? Justice and the Distribution of Employment" en A.A.V.V., (editor Kory P. Schaff) Philosophy and the Problems of Work: A Reader, Bostón, Rowman \& Littlefield Publishers, págs. 562-607.

BABEUF, Grachus, Conspiration pour l'églité, Bruselas, Librairie Romatique, 1828.

BASTIAT, Frédéric, "Libertad como Competencia", en Bastiat Selección de Escritos, Atenas Editores Asociados (versión electrónica).

BECKER, August, Was wollen die Kommunisten?, Lausana, Kommunistischer-Verein, 1844.

Blanc, Louis, Catéchisme des socialistes. París, Au bureau du nouveau Monde, 1849.

BLANC, Louis, "Eclaircissement sur les doctrines du Luxembourg", en Le Nouveau monde: journal historique et politique, París, Bureau D’Abonnement, 1849, Volumen 2, págs. 126 a 142.

BLANC, Louis, Histoire de la révolution française, Vol. 1, Labrairie du Figaro, París, 1846.

BLANC, Louis, Historie de la revolution de 1848, T. II, París, Librairie Internationale, 1870 .

Blanc, Louis, La Révolution de Février au Luxembourg, París, Michel Lévy Frères, 1849.

Blanc, Louis, Organisation du travail, $5^{\mathrm{a}}$ ed. París, Au Bureau de la Société Fraternelle, 1846. 
Blanc, Louis, Organistaion du Travail, 9ª ed, París, Au Bureau du Nouveau Monde, 1850.

Blanc, Louis, Révélations historiques en réponse au livre de lord Normamby, Brúselas, Mleline, Cans et Compagnie Editeurs, 1859.

Bovens, Luc y LuTz, Adrien, "From Each according to Ability; to Each according to Needs: Origin, Meaning, and Development of Socialist Slogans", History of Political Economy, vol. 51:2 (2019), págs. 237-257.

BREZHNEV, Leonid I., "Acerca del proyecto de Constitución (Ley Fundamental) de la Unión de Repúblicas Socialistas Soviéticas y de los resultados del debate de todo el pueblo", en Anuario URSS '78, Agencia de Prensa Novosti, Moscú, 1978, págs. 22-28. Accesible en https://www.marxists.org/espanol/brezhnev/1977/octubre/04.htm, (último acceso el día 22 de julio de 2020).

Bunge, Mario y GaBetTA, Carlos, ¿Tiene porvenir el socialismo?, Buenos Aires, EUDEBA, 2014.

Busky, Donlad, F., Communism in History and Theory: From Utopian socialism to the Soviet Union, Vol. 3, Connecticut, Preager, 2002.

CABET, Etienne, Viaje por Icaria, (trad. Francisco Javier Orellana), Barcelona, Imprenta y Librería Oriental, 1848.

CABET, Etienne, Voyage en Icarie, París, Au burueau du populaire, 1846.

CoHEn, Gerald A., Karl Marx's Theory of History: A Defense, Princeton, Princeton University Press, 1978.

CoHEn, Gerald A., If You're an Egalitarian, How Come You're So Rich?, Massachusetts, Harvard University Press, 2000.

CoLE, George Douglas. H., Historia del pensamiento socialista, I: Los precursores, 17891850 (trad. Landa, Rubén), Ciudad de México, Fondo de Cultura Económica, 2020 (orig. 1954).

DE LA HARPE, Jean-François, Cours de littérature ancienne et moderne, Vol. 3, París, Chez Firmin-Didot Frères, Fils et Ca , Libraires, 1863 (original 1789). 
DE PABLO, Oscar, "El a cada quien de acuerdo a sus necesidades de Marx: una interpretación antiutópica", publicado en Memoria: Revista de crítica militante [en línea]. Accesible en https://revistamemoria.mx/?p=641 (último acceso el 31 de julio de 2020).

Elejabeitia, Carmen, Liberalismo, marxismo y feminismo, Barcelona, Anthropos, 1987.

Elster, Jhon, An Introduction to Karl Marx, Cambridge, Cambridge University Press, 1986.

ELSTER, Jhon, "Exploitation, Freedom, and Justice”, en A.A.V.V. (Eds. J. R. Pennock y J. W. Chapman), Marxism, Nueva York, New York University Press, 1983, págs. 277304.

Fetscher, Iring, Socialismo. De la Lucha de Clases al Estado Providencia, Barcelona, Plaza \& Janes, 1977 (orig. 1968, J. Ruíz).

FOURIER, Charles: Traité de l'Association domestique-agricole, trabajamos con la versión incluida en Oeuvres complètes, Paris, Société pour la propagation et pour la réalisaton de la theorie de Fourier, 1843 (orig. 1822 bajo el título, Théorie de L'unité universelle).

FURNER James, Marx on Capitalism. The Interaction-Recognition-Antinomy Thesis, Leiden/Boston, Brill, 2019.

GARnIER, Joseph, Traité D'Économie Politique Sociale ou industrielle, París, Garnier Frères, Guillaumin et $C^{a}$, 1868.

GIDE, Charles y PEnIN, Marc, Coopération et économie sociale: 1904-1926, París, L Harmattan, 2005.

GILABERT, Pablo, "The Socialist Principle "From Each According To Their Abilities, To Each According To Their Needs", Journal of social philosophy, vol. 46, núm. 2, 2015, págs. 197-225.

HuIDs, Peter, Marx's Concept of the Alternative to Capitalism, Leidne/Bostón, Brill, 2012 ,

ILAS-ROCHERIEUX, Yolène, "Totalitarisme et syndrome utopique: la spéficité de communisme" en A.A.V.V. (dir. Courtois, Stéphane), Quand tombe la nuit: origines et émergence des régimes totalitaires en Europe, Lausanne, L’Age d’Homme, 2001, págs. 281-291. 
JoHnston, David, A Brief History of Justice, Oxford, Wiley-Blackwell, 2011.

KyMLICKA, Will, Contemporary Political Philosophy, Nueva York, Oxford University Press, 2002.

LOUVET, Louis, Curiosités de l'économie politique, París, Adolphe Delahays, 1861.

Luján PAlma, Eugenio: El derecho y la fuerza. Miguel de Unamuno: Desvelando la unidad de sentido y de su pensamiento, Sevilla, Punto Rojo, 2017.

MANIQUET, François, "De chacun selon ses capacités à chacun selon ses besoins, ou (même) plus, s'il le souhaite", en Revue économique 2017/1 (Vol. 68), págs. 119 a 129.

MARX, Karl, Crítica del programa de Gotha, Elaleph, 2002 (origi. 1875). Libro electrónico.

MARX, Karl, El 18 de brumario de Luis Bonaparte, Madrid, Fundación Federico Engels, 2003 (orig. 1852).

MARX, Karl y ENGELS, Frederich, La ideología alemana. Crítica de la novísima filosofía alemana en las personas de sus representantes FeuerbachI B. Bauer y Stirner y del socialismo alemán en las de sus diferentes profetas (trad. Roces, Wencesalo), Barcelona, Ediciones Grijalbo, 1974 (orig. Publicado en 1932, escrito entre 1845 y 1846).

MENGER, Anton, El derecho al producto íntegro del trabajo (edición y estudio preliminar «derechos sociales y Estado democrático social en Antón Menger» Monereo Pérez, José Luis), Granada, Editorial Comares, 2004 (orig. 1886).

MERSON, Ernest, Du Communisme, réfutation de l'Utopie Icarienne, París, Garnier Frères, 1848.

Morelly, Étienne-Gabriel, Code de la Nature, París, Paul Masgana, Libaririe-Éditeur 1841.

LEVASSEUR, Émile, Histoire des classes ouvrières en France depuis 1789 jusqu'à nos jours, T.II, Librairie Hachette, París, 1867.

LOMENIE, Louis-Léonard, Galerie des Contemporains illustres, par un homme de rien, T.II., Bruselas, Meline, Cans, et compagnie, 1848. 
PALMIERI di Micciché, Michel, A chacun selon sa capacité, à chaque capacité selon ses oeuvres, París, Chez Dent, 1831.

PeCHAN, Hermann, Louis Blanc als Wegbereiter des modernen Sozialismus, Viena, Jena, G. Fischer, 1929.

Proudhon, Joseph, De la justice dans la révolution et dans l'église, T.II, Bruselas y Lepizig, Schnée Libraire Éditeur, 1860.

Proudhon, Joseph, Oeuvres complétes, Vol. 10, París, Librairie Internationale, 1868.

RAWLS, John, “A Theory of Justice”, en A.A.V.V., (edt. Kory P. Schaff), Philosophy and the Problems of Work: A Reader, Bostón, Rowman \& Littlefield Publishers, págs. 501561.

RENARD, Edouard, Louis Blanc. Sa vie, son oeuvre, Librairie Hachette, 1923.

SAINT-Simon, Claude-Henri, Le Producteur: journal philosophique de l'industríe, des sciences et de beaux arts, T. IV., París, Galerie de Bossange Père, 1826.

SAVIDAn, Patrck, Dictionnaire des inégalités et de la justice social, París, Presses Universitaires de France, 2018.

TARA, Vasile y Müller Montiel, Ángela, "La Evolución De La Idea De Desaparición Del Estado En La Teoría Marxista”, en Revista Mexicana de Sociología, vol. 24, núm. 1, 1962, págs. 75 a 86.

TOURNIER, Maurice, Propos d'étymologie sociale. Tome 2: Des mots en politique, Lyon, Ena Éditions, 2002.

Trevor, Cairns, El poder para el pueblo (trad. Tiara Ferrer, Montserrat) Torrejón de Ardoz, Akal, 1991.

TROTSKY, Leon, La revolución traicionada. Versión electrónica accesible en https://www.marxists.org/espanol/trotsky/1936/rt/10.htm\#seg\%201 (último acceso el día 3 de agosto de 2020).

UliÁnOv, Vladímir Ilich, The State and Revolution. Versión electrónica accesible en https://www.marxists.org/archive/lenin/works/1917/staterev/ch05.htm\#s3, (última visita el 3 de agosto de 2020). 
VALERO, Juan: "Los precursores del socialismo", Tiempo de Historia, núm. 86 (1982), págs. 14-33.

VIDAL, François, De la répartition des richesses, ou, De la justice distributive en économie, París, Capelle Libraire-Editeur, 1846.

Vidal Molina, Paula F., "La teoría de la justicia social en Rawls", Polis, núm. 23/2009. Accesible en http://journals.openedition.org/polis/1868 (último acceso el 12 de julio de 2020).

Vigo SERRALVO, Francisco, El derecho al trabajo, un primigenio y alternativo proyecto de Estado social. Reflexiones para el debate sobre la cuestión social contemporánea, Cizur-Menor, Aranzadi, 2019.

WEBER, Max, Economía y sociedad (trad. Medina Echavarria, José et al.), Madrid, Fondo de Cultura Económica, 1964 (orig. 1922). 